Portland State University

PDXScholar

1978

\title{
An exploration into the field of hospital social work
}

Timothy D. Haley

Portland State University

Follow this and additional works at: https://pdxscholar.library.pdx.edu/open_access_etds

Part of the Social Work Commons

Let us know how access to this document benefits you.

\section{Recommended Citation}

Haley, Timothy D., "An exploration into the field of hospital social work" (1978). Dissertations and Theses. Paper 2765.

https://doi.org/10.15760/etd.2761

This Thesis is brought to you for free and open access. It has been accepted for inclusion in Dissertations and Theses by an authorized administrator of PDXScholar. Please contact us if we can make this document more accessible: pdxscholar@pdx.edu. 
AN EXPLORATION INTO THE FIELD OF

HOSPITAL SOCIAL WORK

$$
\text { by }
$$

TIMOTHY D. HALEY

\title{
A practicum submitted in partial fulfillment of the
} requirements for the degree of

\author{
MASTER OF SOCIAL WORK
}

Portland State University

1978 
TO THE OFFICE OF GRADUATE STUDIES AND RESEARCH:

The Advisors approve the practicum of Timothy $D$. Haley presented May 19, 1978.

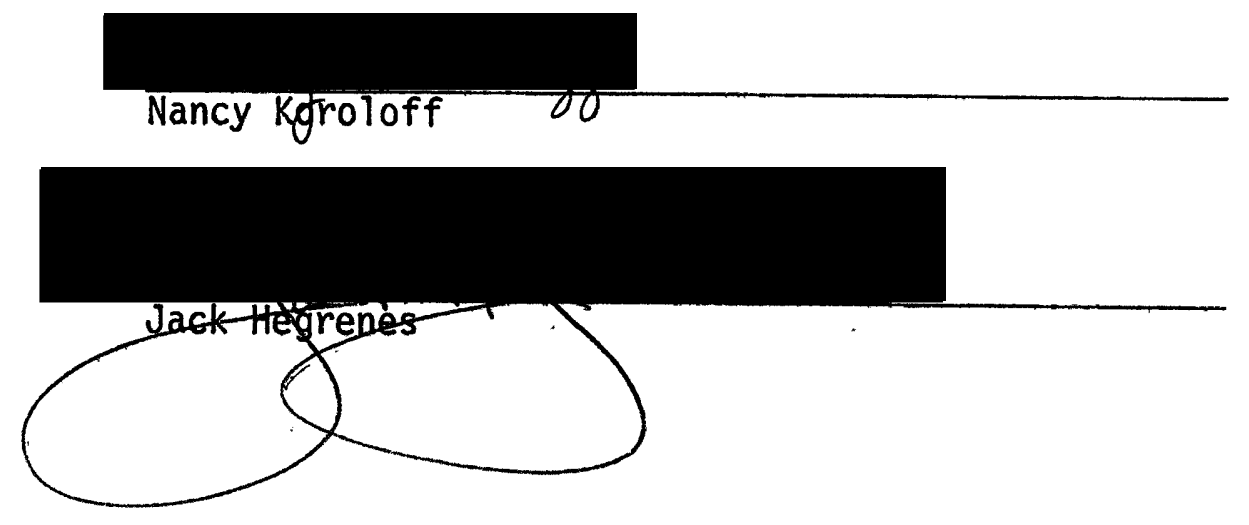




\section{ACKNOWLEDGMENTS}

Throughout this year, while meeting with/talking to my advisors about this projecr, I often wondered, "Where do they find the time?" The truth of the matter is, they did not have any time. Yet they were always somehow available when needed to offer help, assistance, and guidance. My thanks to Nancy Korol off and Jack Hegrenes. 


\section{PREFACE}

When I initially applied to graduate school, I had in mind to "specialize," after the first year, in hospital social work. For a number of reasons, I had, in the past, always liked the "feel" of the hospital setting. Also, I had always been impressed with the hospital social workers that I had encountered during my previous jobs. They seemed to have been in key positions to provide some unique services that were, so to speak, on the "cutting edge" of life/society. In short, my desire to "specialize". was based more on impressions, rather than on actual job experiences within a hospital or knowledge of what hospital social work really was.

Toward the end of my first year of graduate school, I received my second year field placement; it would be in a hospifal setting. The news actually represented the "unofficial" beginning of this project, for I was immediately struck by two thoughts: '(1) the realization of how little I knew about hospital social work, and (2) a curiosity over what exactly this profession was that I had managed to get myself into.

As a way to acquire some knowledge and to satisfy some of my curiosity and interest, I began to read about social work in a hospital setting. The more I read, the more engaged I became. The literature seemed to suggest that hospital social work was, for a variety of reasons, a struggling profession. Although rewarding for some, it seemed to also have the capacity to be, in general, quite frustrating for many others. This really interested me. Why were workers from this 
profession frustrated? What kinds of problems were unique unto hospital social work? Did such dissatisfaction exist in actuality, or only on the printed page? Consequently, in order to continue exploring this field (i.e., a field in which I was to now have my second year of field placement) as well as to, more specifically, find out about hospital social workers in Portland, Oregon, I decided to develop a research project around what hospital social workers did think and feel about the environment in which they worked. Such a project, I felt, could definitely influence the direction(s) of my own career. 
TABLE OF CONTENTS

PAGE

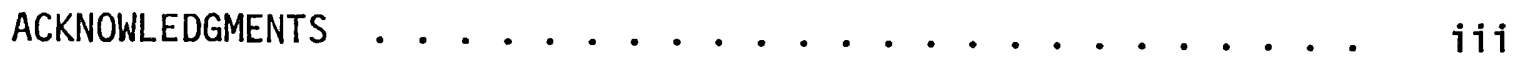

PREFACE .............................. iv

LIST OF TABLES ............................... ix

LIST OF FIGURES ....................... . . . $\mathrm{x}$

CHAPTER

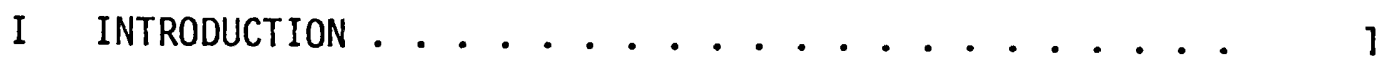

Significance ................ 2

II LITERATURE REVIEW ...................... 3

The History of Hospital Social Work ...... 3

Other Studies ............... 22

Review of Research

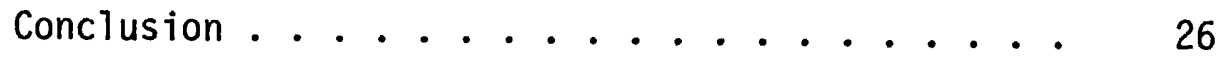

III RESEARCH DESIGN AND METHODOLOGY . . . . . . . . 28

The Instrument . . . . . . . . . . 28

The Respondents ............. 31

Collection of Data ........... . . . 32

Attitudinal Responsiveness ......... 33

Testing Procedures . . . . . . . . . 34

Analysis of Data ............ 35 
IV FINDINGS ......................... 37

Introduction ............ . . 37

Hospital A............... . . 38

Summary (Hospital A)

Hospital B............... 40

Summary (Hospital B)

Hospital C................ 43

Summary (Hospital C)

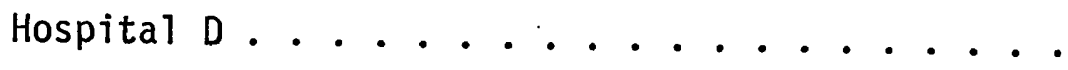

Summary (Hospital D)

Hospital E................... 48

Summary (Hospital E)

Hospital F.............. . . 50

Summary (Hospital F)

Hospital G............... . . 53

Summary (Hospital G)

Hospital H................

Summary (Hospital H)

Combined Profiles .............

Relationship Dimensions

Personal Growth/Development Dimensions

System Maintenance and System Change Dimensions

Variance of Standard Scores ..........

62

Discussion of Variance

Workers

Students

Conclusion ................. 
$\checkmark$ CONCLUSIONS AND RECOMMENDATIONS ......... 70 Conclusions ............... 70 Recommendations ........... 75

SELECTED BIBLIOGRAPHY . . . . . . . . . . . . . 79 APPENDICES

A COVER LETTER . . . . . . . . . . . . . . . . 84

B EXPLANATION OF PROJECT . . . . . . . . . . 86

C STANDARD SCORES FOR DIRECTORS/WORKERS/STUDENTS . . . 87 


\section{LIST OF TABLES}

TABLE

PAGE

I Work Environment Scale Subscale Descriptions . . . . 30

II Mean and Variance of Standard Scores . . . . . . . 63

III Standard Scores (Directors) . . . . . . . . 87

IV Standard Scores (Workers) . . . . . . . . 87

V Standard Scores (Students) ............ 88 


\section{LIST OF FIGURES}

1 Hospital A.................. 40

2 Hospital B...................... 43

3 Hospital C............................. 45

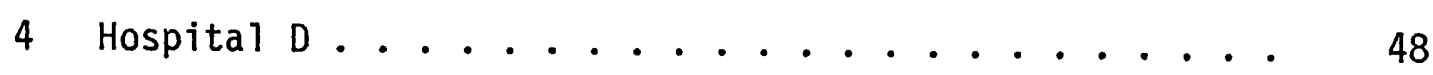

5 Hospital E.................... 50

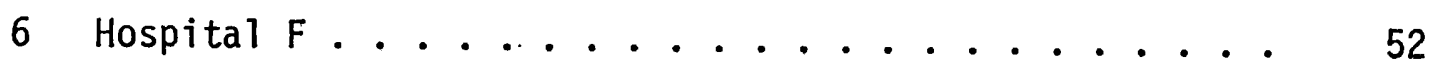

7 Hospital G................. 55

8 Hospital H.................. 57

9 Combined Profiles ............... 58 


\section{CHAPTER I}

\section{INTRODUCTION}

The purpose of this project is to explore the field of hospital social work to see what, if any frustrations, problem areas, and/or dissatisfactions exist among those who work in this professsion. In order to accomplish this task of exploration, the project is composed of three parts. The first segment is the literature review (Chapter II). It is divided into a brief history of hospital social work and other studies that have been done on hospital social workers. It is hoped that the combination of both of these components will reflect the struggles, strengths, and problems of the profession, therefore giving the reader a sense of the profession's background. Secondly, by attempting to capture some of the "roots" and research involving hospital social workers, hopefully, a context will be provided as the project takes a look at hospital social workers in Portland, Oregon.

The second part of the project consists of a research study. It attempts to assess the attitudes of hospital social workers in Portland toward the environment in which they work. By doing this, the research portion will contribute, more specifically, to the overall purpose of the project. This section includes the design and methodology of the research (Chapter III) as well as the findings (Chapter IV). All of the eight hospitals in the Portland area having social service departments are involved in the study. In addition, the ten second year MSW 
students from Portland State University who were placed in hospital settings for their second year of field placement, are also included in the research segment of the project.

The third part is comprised of the conclusions and recommendations. It is hoped that this section will bring together both the first and second parts of the project and in so doing, formulate the end results of the intended task, an exploration into the field of hospital social work. Finally, a short section will follow on recommendations for the future.

\section{SIGNIFICANCE}

To the best of this author's knowledge, only one other study even touches upon what hospital social workers think and/or feel about their positions within a hospital setting. Hopefully, this project will help workers and directors of hospital social service departments to better assess, understand, and explore the strengths and weaknesses of the profession both within their own departments and the field as a whole.

It is believed that this is of continual necessity if the profession is to fully realize i.ts potential in the future. 
CHAPTER II

\section{LITERATURE REVIEW}

To begin the exploration into the field of medical social work in hospital settings, the author believes that it is necessary to consider both a brief history of the field as well as other studies that have been done involving hospital social workers. By having both of these components comprising the literature review, the intent is to provide the reader with a context in which to view the actual research portion of this project.

THE HISTORY OF HOSPITAL SOCIAL WORK

Hospital social work officially began in England in 1895 when an experienced worker from the London Charity Organization was stationed at the entrance desk of the Royal Free Hospital (Cannon 1952). This was the result of a long twenty-year effort by the society and its secretary, Charles Loch. In a sense, the position was a compromise. From the hospital's standpoint, the "hospital almoner's" function was "to review applicants to the dispensary and to exclude those unsuitable for care" (Ibid., p. 8). However, Charles Loch had other ideas. While accepting the hospital's concern that as an institution it was being abused by those who were not proper subject for gratuitous medical charity, Mr. Loch also realized that there were often economic considerations that had to be taken into account when a person went into the 
hospital (Ibid.). In short, amidst the role of "investigator," there was the society's belief that the social aspects of medical aid to the poor should be a necessary consideration. Functionally, this meant that while the worker was investigating the financial circumstances of patients, she would also link medical charities with other community agencies (Lubove 1965).

Although the United States cannot lay claim to the "official" beginning of hospital social work, it did contribute immensely to the early development of the field. In this country, the latter part of the nineteenth century had a particularly explosive quality about it. To say the least, the entire country was engrossed in change. Unrestrained industrial development was giving rise to growth in urban communities; there was a tremendous influx of immigrants; and, among other things, scientific medicine, with its technological advances, was giving birth to the "modern hospital." In fact, with regard to the latter, the hospital was the first of the social institutions to feel the pressure of the "rising tide" (Cannon 1952, p. 35). More people in crowded environments meant an increase in disease . . dysentery, pneumonia, typhoid, cholera, and later, above al1, tuberculosis (Lubove 1965).

Meanwhile, amidst the change, a new scientific theory concerned with disease and sickness was emerging. Previously, ill heal.th was' thought to be the result of a visit from some kind of supernatural force over which no one had any control (Pelton 1910). However, in 1881, it was discovered that there was a positive link between disease and hygiene; the "germ theory" had arrived (Lubove 1965, p. 24). With it, there was the realization that there were social sources of disease. 
Dangerous conditions could invite germs that, in turn, could spawn i11ness. Hence, if one was to be concerned with the health of the poor, there would also have to be a concern for their working and living conditions as well, for there was an inseparable relation between a diseased environment and a diseased man.

Before the scientific discovery of germs, there were a few people who had vision. Most notably, Florence Nightingale understood the "social sources" of disease (Pelton 1910). She, in turn, so impressed Dr. Elizabeth Blackwell that in 1853, Ms. Balckwell founded the New York Infirmary for Women and Children (Cannon 1952, p. 23). Located on the lower east side, the Infirmary served primarily the poor by reaching out into the homes. Unlike the hospitals, careful follow-up work was done on discharged patients. Ms. Blackwell even became involved in social reform by advocating for better housing. Both she and her staff were well aware of the relation between living conditions and disease. This was an amazing realization since Dr. Blackwell arrived at this conclusion a quarter of a century before the germ theory. At the Conference on Charities and Corrections in 1910, Dr. Blackwe11's New York Infirmary would be called "the prototype of hospital social work today" (Pelton 1910, p. 333).

By the turn of the century, social work was beginning to emerge as a profession amidst stirrings of social consciousness (i.e., the progressive era) (Cannon 1952). Again, industry, urban growth, immigrants, technological advances, etc., were all pressuring society to begin responding to unmet needs. One outcome of this pressure was a response on behalf of charity organizations. Since there was an increase in the 
numbers and visibility of poor people, beginning in 1898, the New York Society offered a six-week summer session for students of philanthropy to help them expand their awareness of overall society conditions (Ibid., p. 46). It is worthy to note that during the summer session of 1901, three days were given to the discussion of medical charities (Ibid.). In 1898, another important event occurred that would be of "root" significance to the field of hospital social work. During that year, Dr. Charles Cabot became the "Physician to Outpatients" at Massachusetts General Hospital in Boston (Ibid., p. 48). In his previous work with children, he too realized the importance of a child's background and environment in relation to the immediate medical problem. Yet the now "modern hospital," while feeling the pressure of the country's vast social changes, seemed isolated from the community that it was serving. The medical profession was absorbed in scientific discovery. There was virtually no preventative outreach into the communities even though there was more sickness and disease than this country had previously known. Dr. Cabot, by being in charge of outpatients, was particularly feeling overwhelmed, helpless, and isolated. Such feeling spompted him, in 1903, to visit Johns Hopkins medical school. Here Dr. Charles Emerson was conducting a novel experiment in social medicine (Lubove 1965). Essentially, Dr. Emerson's program combined "friendly visiting" with medical education in order to better understand patient care (Ibid.). To "treat" a patient, therefore, also meant taking his social environment into serious consideration. Only in doing this, Dr. Emerson felt, would the quality of medical training improve. Dr. Cabot completely agreed with this "new" idea: 
In October of 1905 , as a direct result of the advocacy on behalf of Dr. Cabot, "a nurse who had had some settlement experience was installed at the Outpatient Department of the Massachusetts General Hospital" (Pelton 1910, p. 335). This event represented the "official" beginning of hospital social work in this country. Her duties were "to investigate and report to the doctors domestic and social considerations, bearing on diagnosis and treatment" (Cannon 1952, p. 48); she was also to connect patients needing charitable help with the proper agencies (Pelton 1910). Dr. Cabot believed that such social services would "overcome the hospital's depersonalization and isolation from the social roots of disease" (Lubove 1965, p. 28).

The year 1905 earmarked not only the beginning af a new profession, but it also marked the beginning of a long struggle for professional validation. The vast majority of physicians felt very strongly that social involvement with patients had little relation to medical theory and practice (Ibid.). Secondly, doctors felt that they were the ones who were officially responsible for a patient's medical care. Their domain was being invaded by "outsiders" who naw had access to a patient!'s medical record. Both physicians and administrators alike felt that the primary duty of the worker should be to prevent the abuse of the public hospital by those who could afford care elsewhere (Butrym 1967) . . Tike the hospital almoners in England. However, as the social services expanded within a year at Massachusetts General to a few "trained" workers and fifty or so volunteers, the new department still saw their primary task as helping, in any way possible, patients and their families; this alone justified their existence (Cannon 1952, 
p. 65). And by the very nature of the duties of social services, the workers saw themselves as belonging to both the hospital and the community. Like with Dr. Elizabeth Balckwell's Infirmary, the hospital workers saw as their task the continuous social follow-up on patient care once the patients were discharged from the hospital. Nevertheless, the stage was set from the beginning for a long conflict that would continue to the present: What exactly were the duties of hospital social workers? How would their tasks differ from good nursing? How would their contribution really affect treatment and diagnosis? Were they to be the servant of the physician? How active were they to be in social reform?

It is to the credit of the profession that these early workers would not be denied. By 1911, there were forty-four hospital social service departments in eight states and fourteen cities, seventeen of which were located in New York City (Ibid.,.p. 92). With Massachusetts General as a mode1, they had developed keen survival tactics in order to prove their worth. For example, at Massachusetts General, after social services were first assigned to a small, quiet, obscure room in the outpatient clinic, the head worker requested that the "department" be transferred to "an unused corner of a busy, noisy corridor where there was constant passing of both patients and doctors" (Ibid., p. 65). To demonstrate the value of services, such a move represented more than common sense... the request had vision.

However, the new profession was not without its problems. Among other things, a variety. of activities were happening under the "hat" called "hospital social work." In 1907, for example, one hospital in New York City appointed a "social worker" with experience as a financial 
investigator whose main task was to assure that the trust funds supporting free beds might be responsibly administered (Pelton 1910). Virtually all social workers, however, came out of a nursing background which raised other questions: How were workers to be trained? And again, how would their role make treatment more effective? In addition, by 1910 , social workers were now involved with patients on the wards and were supervised by a nurse "employed as the executive assistant to the admitting physician" (Ibid., p. 336). Was this to be considered hospital social work? After a11, social workers were paid by voluntary sources; they worked independently in both the community and hospital (i.e., limited, of course, to the outpatient clinics of hospitals); and their work was to be among the poor. Now, on the wards within the hospital, did this mean the hospital would help pay the salary? Should they not work in the community? Should they have contact with patients other than the hard luck poor? All of the above concerns. led the 1910 Conference on Charities and Corrections to proclaim: "What is hospital work? . . the work itself is still undefined and upon investigation; [it] proves to be somewhat capricious in form" (Goldstein 1910, p. 342). Such a claim would continue to the present: "Despite a long and honored tradition of social work in hospitals, considerable confusion about its roles and services still exists" (Schoenfield 1975, p. 93).

It is noteworthy to mention that the 1910 Conference on Charities and Corrections was also exceptionally visionary for the new profession. As the Conference progressed, it became evident that for the first time serious thought was given to the formulation of a professional identity. It spoke first to the institutional setting of hospital social work: 
. . the hospital is primarily a public institution and should serve the public in the largest way; it is a social institution and should fulfill its social functions wisely and completely (Goldstein 1910, p. 347).

It then spoke to the issues of identity and principles:

The social worker possesses and holds, not a medical and not an institutional, but a social viewpoint. His research and experience teach him that in all social distress the family is the unit of suffering and therefore, must be the unit of treatment . . . this is the first principle (Ibid., p. 342).

Since much of the social work of the day involved the function of aftercare, those present at the convention also heard some crisp words regarding this subject. For the speaker, Sidney Goldstein, expressed that no case is socially closed until the patient and the family are socially rehabilitated and reestablished since:

- . aftercare does not mean the disbursement of a few cents for carfare or the distribution of a few pieces of clothing; it does not mean merely letters to employment agencies or cards of reference to relief organizations. It should not even end with a period of two weeks in a convalescent home . . . otherwise, it closes a case at the very moment when it ought to be kept wide open (Ibid., p. 334).

Finally, the issue of hospital social work education was again addressed:

Special training includes hospital experience; [it] includes medical knowledge; [it] includes some idea of nursing.. . [and] to these must be added social passion (Ibid.)...

These were all important words. The speaker said, in essence, that while the social service department should be an inseparable part of the hospital, it also had a unique role. The patient was to be seen and worked with in a social context. This would involve the use of the community/outreach/reform for the sake of overall social rehabilitation. A new profession was, indeed, beginning to emerge by perhaps selling itself first on a national level to its fellow social workers. This 
represented the first of many calls to hospital social workers: "Let us get our own house in order."

The profession now was clearly on the move. Hospital social workers began to express a "great passion" for professional education (Lubove 1965, p. 33). As a result, early in 1912, the Simmons College School of Social Work offered a second year of education to those who wanted specialized training in hospital social work (Cannon 1952, p. 113). By the end of 1912, in order to get a job as a social worker at Massachusetts. General, the hospital required that the person be a graduate of this two-year program (Lubove 1965). Hospital social work, therefore, became the first branch of social work to require a full two years of training.

With the beginning of education for hospital.workers, there also began yet another controversy that would continue to the present. The issue naturally arose, "What should go into the educational curriculum of workers wanting to serve in hospitals?" In a broad sense, the curriculum at Simmons reflected what the majority of hospital social service departments were doing at the time, understanding the social dynamics of disease and illness. What the early educational endeavors were not doing, however, was exposing social workers to the roots of scientific thinking which functionally.meant seeing illness from the doctor's medical perspective (Butrym 1967). Two cultures were being formed that resulted in. a lack of communication and only more conflict; the doctors had their. science and the workers had their social context. Neither educational perspective provided training to understand that of the other side. It is fair to say, however, that workers were expected to 
grasp the technical language of the doctors if they were to earn their "keep." Unfortunately, doctors were never required to do likewise irregardless of the germ theory discovery. Mary Richmond's Social Diagnosis, written in 1917, stated:

It is evident that both groups of public servants--the social and the medical--will serve the public best when they have thoroughly mastered in all its details the technique of: working together (Richmond 1917, p. 209).

So again, another stage was set for an embittered conflict. At least now, though, with an educational structure, social workers could begin to develop and refine their own techniques.

Meanwhile, besides those in education, there were other gains for the profession during the second decade of the twentieth century. Such events as the influenza epidemic of 1918 provided hospital social workers with opportunities to do much in the way of follow-up care and preventative outreach in the community. It was also during this decade that World War I began. Entire communities felt the impact of the war. Families were torn apart as men were shipped overseas; household incomes were reduced; "public" hospitals were feeling the pressure of people who could not afford to receive care elsewhere. In the outpatient clinics, hospital workers had more to do than they could handle. In addition, the Red Cross, Army, and Navy wanted help from social workers which resulted in a serious drainage from hospital social service departments. The new profession responded to this dilemma. In 1918, the American Association of Hospital Social Workers was founded in order to maintain hard-fought gains and hold the profession together (Lubove 1965, p. 125). At its first convention, the delegates developed minimum, uniform criteria of practice. The hope, of course, was that the criteria would 
give further credence to the profession. The strategy seemed to have an infleunce. By 1919, again at Massachusetts General, for the first time, a hospital social service department became an official part of the hospital (Cannon 1952, p. 129). After almost fifteen years, the profession had earned its "keep." No longer was it under the supervision of a benevolent Social Service Committee; no longer was it to be paid out of voluntary funds. Now, the department would be directly responsible to the hospital administrator. It would become one small part of a complex institution. However, like with other aspects of hospital social work, there would be a price in becoming an official part of the hospital that would be realized to the present: "Within health settings, the social worker has been placed in an ancillary status that has imposed control by other professions" (Nacman 1975-76, p. 135).

The years from 1920 to 1930 represented a period of selfconsciousness for the field of social work as a whole. In no other branch of social work was this more true than with hospital social work (Cannon 1952). To date, there had been significant gains . . the Simmons College program, a formal organization, and in some hospitals, the recognition of being an official part of hospital functioning. An identity, most assuredly, was beginning to take some kind of form. However, there also continued to be, as previously mentioned, a great diversity of activities happening under the name of "hospital social work." Secondly, and perhaps more importantly, the: unique "social viewpoint" of hospital workers was becoming increasingly clouded as departments became an official part of the hospital. Social casework and community outreach were rapidiy becoming secondary to the now primary work of being 
on the wards. The influence here of psychiatry and psychology cannot be stressed enough. For "personality problems" were now becoming another area for hospital social workers to consider... By the late 1920s, the American Association of Hospital Social Workers agreed:

. . that the caseworker's task included, "mobilization of measures for the relief of the patient and his associates," but significantly, [the Association] denied that community and public health work, or improvements of conditions in industry and education were among the worker's main purposes (Lubove 1965, p. 108).

"Self-consciousness," it seemed, was resulting in a much different direction from the early work in outpatient clinics . . social rehabilitation and reform.were taking a definite "back seat" to hospital ward work.

Hospital social work, therefore, was slowly finding itself between "a rock and a hard place" .... and this is yet another struggle that has continued to the present, On the one hand, as workers wanted to become more a part of the "hosptial team," physicians, for the most part, denied them membership due to their lack of medical knowledge and skills. On the other hand, while adopting a psychological model for casework, hospital workers were losing much of their uniqueness as a profession. In the meantime, hospital social service departments had to continually prove themselves since they were often considered to be a financial burden.

Although the hospital worker's work in the community had greatly diminished after becoming an official part of the institution, the hospital social service department was still more involved in the social well-being of the patients than anyone else within the hospital setting. There was still flexibility within the profession as well. If the 
patient could be better served by coordinating both community and hospital endeavors, the social worker usually played a central role in implementing the strategy. This was particularly evident during the depression years. Hospital social workers were in great demand during the 1930s and there was, generally speaking, more involvement with the community than there had been during the previous decade (Cannon 1952).

This brief flourish of what may be called social. reform/community outreach activities was short-lived, however. For one, the profession's passionate desire to be a member of the "hospital team" continued to take hold throughout the 1940s and 1950s. Although there was little respect on the part of physicians for hospital social work. during this time (Goldstein 1955), the profession continued to stress the fact that social workers "must increase their understanding of physicians" ... their stages of learning, their skills, their feelings and attitudes, etc. (Gordon, ed. 1956, p. 31). This was especially difficult for workers to do since the 1950s continued to bring many great advances in science and, as in the past, social work training did not attempt to deal with scientific thinking. Schools, in fact, completely failed to enhance the contribution to the health care field (Bracht 1974).

Secondly, in the 1940s (i.e., the psychiatric social work period (Lurie 1977)) and 1950s, psychology continued to have an immense impact on hospital social work. Midway into the 1950s it was, by this time, a recognized and accepted fact that hospital social work meant casework service to the individual patient within the hospital; this was the "primary and fundamental activity" of social service departments (Moss 1955, p. 68). "Casework service," of course, now meant a direct concern. 
with first the emotional and then the social problems connected with illness and its medical treatment (Butrym 1967, p. 5).

During the 1940 s and 1950 s, every so often the profession returned to its earlier roots. For example, in 1949, a social service project at the Monte Fiore Hospital in New York City integrated work with the family and work with the patient (Field 1949). This was labeled a "new cooperative step." Basically, a worker would sit down with families at the hospital once/week and interpret medical information, talk about a patient's adjustment to the hospital, and plan for the person's discharge with them. The social service department felt that families had a right to participate in planning for the patient: At this hospital, as at most, the social workers had previously invested all their energies in trying to create a teamwork relationship with the doctors. It was decided after many years of trying to do this, however; that they would take a new and different approach, contact with families. Little did they know that the social service department was following the first principle of hospital social work as designated by the 1910 Conference on Charities and Corrections, working with the family as anit of treatment.

Throughout the 1960s, hospital social work basically continued along the same path that it had wedged out during the 1940s and 1950s. In relation to its earlier roots, this seemed tragic. For during the 1960s, there was a great deal of social upheaval and unrest, similar, in many respects, to the Progressive Era at the turn of the century. Whereas in its earlier days the profession was responsive to the needs of the communities, 
. . the accelerated social demands of the $60^{\prime} \mathrm{s}$ found hospital social work no less vulnerable than medicine to charges of social indifference and limited perception of social responsibility (Rehr, ed. 1974, p. 79).

In a sense, this was the price that the profession had paid for being enveloped by psychology and striving to be a member of the "hospital team." Social reform and community outreach and involvement had died in the midst of developing an inward-looking attitude while avoiding conflict at all costs (Butrym 1967).

It seemed especially ironic that hospital social work had lost its unique "social viewpoint" perspective during this time. Dr. Elizabeth Blackwell, while developing the "prototype of hospital social work," understood the realities of "social sources" of disease and had worked for social reform. And Dr. Cabot himself had been inspired to create a social service department because of the hospital's "depersonalization and isolation from the community." In simple terms, both knew that pauperism produced patients; there had to be a response. Was this so different from. Michael Harrington's words in his now famous book, The Other America, written in 1962? He emphasized, with regard to the aged, that if they had had better medical care earlier, they would not have so many health problems when they were older (Harrington 1962). At the time, this was considered to be a new idea. Yet, many early hospital workers had based their entire life's work on this view. It would be one thing for society and the medical profession (i.e., from the "germ theory" on) as a whole to once again be confronted with this "new idea"; it would be quite another for the hospital social work profession to hear this "new" concept coming from another discipline. This alone was an indication 
of how far the profession had drifted from its roots. Indeed, the price of survival had been high.

As in previous times, however, hospital social work stressed the care of the "whole patient" more than any other profession within the hospital setting (Goldstein 1955). Consequently, in the mid-1960s, while the profession maintained that social casework was its primary task, as in the late 1920s, it did not totally exclude . . . or felt obligated to include. . . the possibility of activities such as consultation, program planning, community organization, and services to groups (Lurie, ed. 1965). Practically, however, "whole patient". care meant seizing every opportunity to present the patient's story to those involved with him within the hospital (Goldstein 1955). For example, a worker might be a patient's advocate at the hospital accounting department, in a staffing with the doctor, or would keep a patient's discharge records, etc. Hospital social work entailed a variety of activities. Thus, even by the 1960s, there were, for the most part, "no standards or staffing patterns in hospital social service departments" (Heyman 1962 , p. 5). The individuality of the patient amidst."total care" was being maintained in various degrees depending upon the hospital.

These central concerns of the 1960s also apply to the current period of the 1970s. For example, although total patient care has continued to be proclaimed throughout the 1970s, the fact is that "little has been accomplished towards unifying psychiatric, social, and medical services within a hospital" (Nacman.1975-76, p. 135). Even so, by 1972, of the 7,800 hospitals in this country, 3,179 of them had social service departments (Bracht 1974, p. 538). For one reason or another (e.g., the 
passages of Title XVIII (Medicare) and Title XIX (Medicaid)), the profession has, therefore, continued to expand. No doubt many individual needs have been met along the way due to. the direct involvement of a hospital social worker. No doubt in many hospitals the departments have more than proven their worth. It is to the credit of the profession that it has tried to be, with Massachusetts General as a model, on a "busy, noisy corridor" of the health care field. The profession's accomplishments should not be minimized. On the other hand, if the profession is to continue to expand, one must look more closely at some of the common problematic areas that have accompanied the profession's growth throughout its development to the present. Perhaps, in some ways, this process has already begun: "The present period, 1970 through 1980, may be characterized as the period of professionalism... It is a time for self-criticism and evaluation ..." (Lurie 1977, p. 420).

From the beginning of the profession, Dr. Cabot was always prophetically asking his hospital social workers: "In what is social casework effective?" (Cannon 1952, p. 132).. The question still has not been thoroughly answered to this day. As decades have passed, in other words, the field "has not clearly defined its role and professional sphere of competence, nor developed data to prove its effectiveness" (Rehr, ed. 1974, p. 47). The 1960s seem to reveal that the farther the profession has gotten from its initial roots via "intra-psychology" and the medical model, the worse this "problem" has become. As a result, a clear, distinct professional identity has yet to be formulated.

Secondly, in tracing the profession from its incipience, one quickly sees that doctors have always been basically resistant to 
hospital social work. In fact, it even seems as if they have played a crucial role in actually intimidating the new profession, struggling to create an identity of its own. For:

. . all too often, with no central power base, the individual worker is forced into a dependent relationship. in which the physician defines and sanctions the role, responsibilities, and degree of professional authority that will be permitted to improve status (Nacman 1975-76, p. 135).

Hence, one has the feeling that since 1905, social workers have had to shuffle behind doctors, attempting to follow in their footsteps in order to receive validation. In the process, while surrendering their unique and visionary social rehabilitative efforts, they have taken on many, if not all, of the "behavioral and organizational characteristics associated with hospital-based medical care." (Rehr, ed. 1974, p. 79). Among these include:

the acceptance of the physician's ultimate control of patient care;

the dominance of the medical mode1 in diagnosis and treatment;

the concentration of intellectual and material resources on crisis-oriented intervention, directed principality to the treatment of the sick patient in the hospital bed; [and] specialty orientation (Ibid., p. 81).

In the meantime, the social work "foot-shuffle" has really not produced dividends. Workers have, for the most part, become captives of the status quo. Excessively dependent on being a member of "the team," there has been an accompanying lack of clarity concerning the nature of the team and their own unique role on it (Butrym 1967). And social workers have still not received an equal respect from physicians for their profession.

The dependence on doctors and on being a member of "the team" has led to another problem that heretofore has only been touched upon. To 
date, the profession has been, in many respects, confined to those areas that others, within the hospitals, have defined as being hospital social work. Horkers have accepted having others define their roles, tasks, and responsibilities in the name of "getting our foot in the door" or "proving our worth." While adopting such a stance, the profession has had little power on the hospital organizational level, thus being open to the domination by lay and medical personnel (Nacman 1975). For if a profession. like that of social wark controls no resources and has no legal authority within a hospital setting (Ibid.), there is little chance that it will have any power. . . and without power, there will be little in the way of change and/or innovation for the good of the profession. As a result, organizationally speaking, hospital social work has not invested the necessary energy into understanding various aspects of the system (e.g., developing keen understandings of organizational politics and pathologies). Directors of hospital social work programs have generally functioned on the level of "earning our keep" or "being all things to all people," rather than continually redefining and renegotiating "social work functioning at increasingly higher levels of responsibility, versatility, autonomy, and authority" (Wax:1968, p. 67). In this way, the profession has helped to perpetuate its seemingly low status in the medical field (Hallowitz 1972).

Finally, in the area of medical social work education, it has been said that when social workers are employed at a hospital, their medical knowledge is approximately equivalent to that of an average Time magazine reader (Rehr, ed. 1974, p. 84). Within a medical model framework, this, of course, has implications as to why co-partnership with 
physicians may be difficult to achieve. Many of the early workers were nurses; they did not have this problem of lack of medical knowledge. As the profession bought into "medical theory and practice," however, social work education failed to adapt. They did not, as stated earlier, "enhance the contribution to the health care field." Some decisions, therefore, need to be made in this area of education. Like with the turn of the century and the 1950s, scientific discoveries continue to be rapid in the 1970s. The issue of hospital social work education can no longer be ignored; for the sake of the profession, it has to be more seriously addressed.

Given this brief overview of the history of hospital social work, a look at the research studies involving hospital workers is now in order. Surprisingly, there are relatively few such studies that have been conducted. Those that this author has reviewed are presented in the next section.

\section{OTHER STUDIES}

There are basically three purposes for examining other studies that have been done involving hospital social workers. First, it is hoped that various issues, problems, and areas of concern will be illuminated. Secondly, it is hoped that a brief examination of the studies will contribute to the understanding of the history of the profession of hospital social work. Thirdly, the author hopes that a presentation of other studies will help the reader to place the research portion of this project into a context. 
Review of Research

Heyman (1963) conducted an eight-month study at Billings Hospital (i.e., the University of Chicago) entitled, "Collaboration between Doctor and Caseworker in a General Hospital." Collaboration was defined as "the continuing activity of the doctor and caseworker in working together for the restoration of the patient to his maximum health potential" (Heyman 1967, p. 286). A total of ninety-six closed cases and twentytwo open cases were analyzed on an ongoing basis. Heyman found, among other things, that doctors specified the means by which a particular problem was to be solved in 75 percent of the cases. And although the doctor identified a problem as being psychological about half as frequently as the social worker,

- . favorable outcomes occurred in more cases in which the worker at no time questioned the doctor's solution to the problem, that is, in cases in which the worker continued to accept the doctor's initial view of the solution" (Ibid., p. 290).

At the University of Michigan Health Center, Katherine and Marvin 01 sen (1968) conducted a study (i.e.,.."Role Expectations and Perceptions for Social Workers in Medical Settings") involving sixteen social workers and thirty-five physicians. The researchers wanted to explore what conflict, if any, existed between social workers and physicians in a hospital as related specifically to their expectations of the social worker's role and their perceptions of each others' expectations. By using self-administered questionnaires, it was found that a considerable amount of conflict existed in both of these areas. Physicians, general$1 y$, were unwilling to grant nearly as many professional responsibilities as the social workers thought they should have. The activities that produced the most conflict between the two professions were those 
involving a psycho-therapeutic approach to the social and/or emotional problems of patients. The least amount of conflict was experienced with concrete activities such as arranging for post-hospital care and/or making referrals for community services.

A number of studies (e.g., Phillips \& Solon 1960; Gordon \& Rehr. 1969; Phillips et. a1. 1971; Berkman \& Rehr 1973) have dealt with the issue of case finding/selectivity. Whereas they all arrived at very similar conclusions, the research by Gordon and Rehr. (1969) seems to be the most thorough. Through exploring the heavy. utilization of hospital services by the aging, they did a study of the referral patterns of 127 cases to the social service department at Mount Sinai Hospital, New York. The issue that clearly emerged was how highly dependent the social work department was on the medical profession's choice of referrals, perceptions, and patterns of intervention. Gordon and Rehr concluded, therefore, that "by not defining its case-finding system, social work relinquishes the right to set its own priorities" (Ibid., p. 41).

There is ample data (reviewed by Nacman 1975-76) to at least demonstrate that "the social worker is viewed within a limited frame of reference by other professionals in the health area" (Nacman 1975-76, p. 133). Specificially, Nacman reviewed three studies which showed that medical personnel, while referring sizable numbers of patients for social work services, primarily perceived the role of social worker as encompassing concrete, instrumental services for patients.

These studies indicate a fundamental difference between the social worker's view of their practice as being concerned with emotional and behavioral problems of patients (affective-expressive tasks) and the physician's more narrow perception that social work is primarity capable of provicing assistance for transportation, location of nursing homes, and the like (instrumentar taskș) (Ibid.). 
Nacman later concluded that if affective-expressive services were present, they were not visible enough to others.

Pfouts and McDaniel (1977) conducted a study of the social workers in the pediatrics departments of twenty-eight teaching hospitals. Through the use of self-administered questionnaires, workers were asked to define their roles and describe their activities. The researchers analyzed the data with respect to the amount of autonomy workers exercised in direct service, teaching and consultation, and research. In answering the question, "Handmaidens or Colleagues?" it was concluded that in some areas of their practice (i.e., teaching and consultation), workers were more autonomous than was believed; in other areas of practice (i.e., relating to direct service and research), the opportunities to achieve autonomy. were not grasped. In other words; regarding the latter, it was felt that constraints upon the profession were imposed by doctors and administrators as well as the way in which hospital social workers defined themselves.

The final study to be reviewed (U11man et a1. 1971) involved 638 hospital social workers. The focus of the study was on, as its title states, "Activities, Satisfaction, and Problems of Social Workers in Hospital Settings." The researchers found that: (1) hospital settings engendered a distinctive professional role for workers, (2) hospital social workers were more likely to be satisfied than dissatisfied with their jobs, and (3) complaints from hospital social workers were distinctive from non-hospital-based workers in that they were less likely to complain about low salaries and more likely to complain of lack of support (i.e., from members of other health professions, especially 
physicians). On the basis of the analyzed data, it was concluded that hospital social work reflected a traditional service orientation toward the individual patient. Such an orientation did not include social action within the larger community or within the hospital itself (e.g., action directed toward the hospital administration). Consequently, it was felt by the researchers that hospital social workers were "perpetuating some of the distressing work conditions about.which they complain: staff shortages, heavy.workloads, few opportunities for promotion, insufficient community resources, and the like" (Ibid., p. 28). The researchers, therefore, felt that it was extremely important for directors to begin making sufficient efforts at program planning.

From the studies found by this author, only the last one (U17man et a1. 1971) directly asked a question about what workers thought and/ or felt about their jobs (i.e., what the research portion of this project explores): "Al1 in a11, how do you feel about the setting where you presently work?" (Ibid., p. 17). To this question, 51 percent stated that they were "very satisfied"; 37, percent said that they were "somewhat satisfied"; and 12 percent were "somewhat or very dissatisfied" (Ibid.). On this portion of the study, it was concluded that "workers were neither more nor less likely to be satisfied than nonhospital workers" and secondly, that directors were "slightly more likely to be satisfied" (Ibid., p. 22).

\section{CONCLUSION}

Hopefully, the combined history and review of other studies has provided a context in which to now view the research portion of this 
project. As one can see, the literature seems to reflect a number of frustrations, problem areas, and dissatisfactions of hospital social workers. The research portion will now examine eight hospital social service departments in Portland, Oregon. In addition, since the area of education was considered in the history of the profession, ten MSW students (i.e., hospital-based) will also be included in the research project. 
CHAPTER III

RESEARCH DESIGN AND METHODOLOGY

THE INSTRUMENT

Data for the research segment of this project on hospital social work was collected by means of the Moos. Work Environment Scale (W.E.S.) (Moos, pp. 16-25). This ninety-item, true-false test. (Form R) seemed ideal for assessing the attitudes of hospital social workers toward the environment in which they worked.

The instrument itself focused on three dimensions of the work environment, all of which seemed to be crucial in understanding what hospital social workers thought and/or felt about their work milieu. These dimensions were Relationships (i.e., among employees and between employees and management), Personal Growth, and System Maintenance and System Change. Each of these three dimensions was, in turn, broken into subscales (see Table I), which included:

A. Relationship dimensions

1. Involvement (I)

2. Peer Cohension (PC)

3. Staff Support (SS)

B. Personal Growth Dimensions

1. Autonomy (A)

2. Task Orientation (TO) 
C. System Maintenance and System Change Dimensions

1. Work Pressure (WP)

2. Clarity (C)

3. Control (Ctl)

4. Innovation (Inn)

5. Physical Comfort (Comm)

The W.E.S. instrument was developed under the direction of Rudolph Moos. An initial 200-item Form (A) of the W.E.S. was created through interviews with individuals from various work groups and by adapting items from other Social Climate Scales to work environmental concerns. The Form (A) was then administered to seventy-five individuals in a sample of five work groups. Once the data were analyzed, a number of items were dropped and/or reworded. In addition, other items were formulated. From these efforts, a 138-item Form (B) of the W.E.S. was developed.

Form (B) was administered to 624 supervisors and/or employees representing 44 work groups. These groups included a wide range of employment situations to insure that the resulting scale would be applicable to all work milieus. Hence, the test was administered to a variety of groups such as: (1) administrative and staff nurses working in a V.A. hospital, (2) faculty members in a nursing school, (3) janitors, maintenance workers, and security officers employed in a university setting, (4) professionals and paraprofessionals in a psychiatric outpatient clinic, (5). employees in a small electronics firm, etc.

The resulting data from the tests of these 624 individuals were then used to develop the revised ninety-item, ten-subscale form ( $R$ ) of 
TABLE I

WORK ENVIRONMENT SCALE SUBSCALE DESCRIPTIONS

Subscales

Dimensions

Relationship Dimensions

1. Involvement (I) Measures the extent to which workers are concerned and committed to their jobs; includes items designed to reflect. enthusiasm and constructive activity.

2. Peer. Cohesion Measures the extent to which workers are friendly (PC)

3. Staff Support Measures the extent to which management is sup(SS) portive of workers and encourages workers to be supportive of each other.

Personal Growth Dimensions

4. Autonomy (A)

Assesses the extent to which workers are encouraged to be self-sufficient and to make their own decisions. Includes items related to personal development and growth.

5. Task Oreinta- Assesses the extent to which the climate emphation (TO) sizes good planning, efficiency and encourages workers to "get the job done.".

System Maintenance and System Change Dimensions

6. Work Pressure Measures the extent to which the press of work (WP)

7. Clarity (C) Measures the extent to which workers know what to
expect in their daily routines and how explicitly dominates the job milieu. rules and policies are communicated.

8. Control (Ct]) Measures the extent to which management uses rules and pressures to keep workers under control.

9. Innovation (Inn)

Measures the extent to which variety, change, and new approaches are emphasized in the work environment.

10. Physical

Comfort (Com)

Assesses the extent to which the physical surroundings contribute to a pleasant work environment.

SOURCE: Moos, p. 17. 
the W.E.S.; the Form (B) tests were rescored using this Form (R). The means and standard deviations were then determined for each subscale of the Form (R) and converted to standard scores. Subsequently, these standard scores were used while developing the profiles. of those in the research portion of this project.

Using internal consistencies (Kuder-Richardson Formula 20), average item-to-subscale correlations and subscale intercorrelations, the psychometric characteristics of the W.E.S. (Form R) were evaluated. The internal consistencies were all in an acceptable range, with the average item-to-subscale correlations being "relatively high".. (Moos, p. 19). The average subscale intercorrelations were around .25, "indicating that subscales measure quite distinct though. somewhat related aspects of work group milieus" (Ibid.).

Again, overall, the W.E.S. seemed to be an ideal instrument for exploring. what hospital workers thought and/or felt about the environment in which they worked.

\section{THE RESPONDENTS}

For the purposes of this study, "hospital social worker" was defined as a social worker who worked on the "nursing unit" of a given hospital; in other words, excluding psychiatric wards and/or outpatient clinics. This definition was decided upon since the major thrust of hospital social work over the years has been on nursing units, not on psychiatric wards and/or outpatient clinics (see Chapter II, "Literature Review"). For example, of the eight hospitals surveyed for this 
study, only two hospitals had workers in outpatient clinics, while only three hospitals had workers on psychiatric wards.

In total, the research involved all eight hospital social service department directors, twenty-five of a potentially eligible twenty-six MSW hospital social workers, all seventeen eligible "others" (i.e., BAs, BSWs, and one case aide), and the ten second year MSW students from Portland State University who were placed in hospital.settings on a "block basis" (i.e., four days/week for two quarters).

\section{COLLECTION OF DATA}

A cover letter (see Appendix A) explaining the project, a permission slip, and self-addressed, stamped return envelope were sent to the directors of the eight hospitals in the Portland area having social service departments. The directors were given a two-week time period by which to.complete and return the permission slip. At the end of the two-week period, those directors not returning the permission slips were called. Phone calls were subsequently made to five hospital social service directors.

Once receiving permission, each director was contacted in order to arrange for an appointment. During this contact, four of the directors expressed concern about the issue of confidentiality, wanting to be assured that the exact procedures of the testing guaranteed confidentiality both for the workers and the hospitals.

In three of the hospitals $(A, B, C)$, totalling nineteen workers including the directors, each eligible worker (i.e., according to the study's definition of "hospital social worker") had to be contacted 
individually to arrange a time for testing to the worker's convenience. As a result, each of these three hospitals was visited three or more times in order to collect the data.

At the five other hospitals, the W.E.S. was administered in a group setting. At three of these hospitals (D, E, G), the director arranged a special meeting specifically for the purpose of having the workers take the W.E.S. At the two other hospitals $(F, H)$, the W.E.S. was administered at a regularly scheduled staff meeting. In addition, of these five hospitals, there were two hospitals $(E, G)$ in which at least one worker was not present and had to be contacted individually to arrange for a separate appointment on another: day. Hence, the data were collected on only one visit at three of the eight hospitals.

\section{ATTITUDINAL RESPONSIVENESS}

While collecting the data, the author experienced various degrees of responsiveness from the individual directors. At one hospital, the director was warm, receptive, and very apologetic for an absent worker; at another hospital, the director failed to mention the prearranged appointment to the staff at a regularly scheduled staff meeting. In the latter instance, when the author arrived, there were no apologies as he was quickly and coldly referred, by the director, to another staff member "to make other arrangements.". At yet another hospital, the reception was "warm" and the author was invited to remain for lunch with the entire staff.

With most of the hospitals, however, the author was received somewhere between the above mentioned extremes. The author met with the 
staff member(s), gave a brief introduction, administered the test, allowed for a short debriefing time, and left.

The one common element in all of the contacts with groups and individuals was the fact that they were always late. With each contact, the author waited anywhere from ten to fifteen minutes at the earliest to thirty minutes at the latest.

\section{TESTING PROCEDURES}

Each group or individual was given an identical explanation (see Appendix $B)$. The test was then passed out and the directions on the front of the test pamphlet. were read. During the taking of the test, any questions that arose were met with the same response, "Answer as best you can." After the first testing experience with a group, it was found that answering questions during the test seemed to precipitate other questions, arouse confusion over the interpretation of test questions, etc.

Once the tests were completed, a short "debriefing time" followed. Individuals were encouraged to express their opinions about the test. The vast majority of the time responses followed such as: "That was interesting; when do we get the results?" "It was provocative; it really made you think about your job." "Can we have a copy of the test?" There were some responses, however, that were not as favorable: "Some of the words were vague." "Some of the questions did not apply to this environment." "The same question was always asked in different ways." 


\section{ANALYSIS OF DATA}

For the purposes of description and exploration, the data were analyzed in order to obtain a profile for each individual hospital as well as an overall Portland profile, broken down into the categories of directors, workers, and MSW students. Due to the extent of the issue of confidentiality that was insisted upon by one-half of the directors and a number of workers, variables such as sex, length of employment, age, etc. could not be considered. Also, for each individual hospital profile, all workers, regardless of educational level (i.e., workers did record their level of education), were combined due to the issue of confidentiality. It was intended that only in the overall Portland profile would the level of education be included. However, because it was found that MSWs and "others". (i.e., BAs and BSWs, etc.) had very similar attitudes about their work environment, al1 workers were combined in the final overall Portland profile (i.e., broken down into the categories of directors, workers, and MSW students).

To develop the individual profiles, the raw scores were averaged, the mean found, and converted to a scale score. All subscales had an average standard score of 50, which was developed by Rudolph Moos in a variety of work settings in 1974 (Moos, pp. 16-25). Therefore, for each subscale, the converted scale score was seen in relation to this standard score of 50 .

With respect to the overall Portland profile, the standard scores from each hospital. (i.e., both the worker and the director profiles) were averaged. in order to find the mean standard score for each of the ten subscales. This same process was followed while determining the 
overall student profile. In addition, on the overall profile, the variance between scores of hospital workers, directors, and students was analyzed for each of the ten subscales. 
CHAPTER IV

FINDINGS

\section{INTRODUCTION}

To continue the exploration into the field of hospital social work, this chapter will report the results of the research portion of the project. A total of forty-two hospital social workers, eight directors, and ten second year MSW students were administered the Moos Work Environment Scale (cf. Chapter III) in order to assess what they thought and/or felt about their positions within a hospital setting.

The findings from each of the eight hospitals. will be presented first. Each hospital will have a combined profile of the workers and an individual profile of the director. There will be a short written summary of what one can generally see from the workers' and the director's profile... and both of these profiles will appear on a graph following the written summary.

The combined profile of all eight hospitals, broken down into the categories of directors, workers, and students will be presented second. Again, along with a graph reflecting these combined profiles, a written summary of what the combined profiles reveal will be presented.

All scale scores are seen in comparison to the standard score of 50, as developed by Rudolf Moos in a variety of work settings in 
1974.* The standard score of 50 represents the overall average for each of the ten subscales, with a standard deviation of 10 . In addition, on the overall hospital profile, the variance from the mean on each of the ten subscales is calculated for directors, workers, and students. A11 scale scores for the hospitals and students are found in Appendix $C$ (see Tables III, IV, and V).

Generally speaking, on the following eight scales, a score of less than 50 is indicative of a problem situation: Involvement (I), Peer Cohesion (PC), Staff Support (SS), Autonomy (A), Task Orientation (TO), Clarity (C), Innovation (Inn), and Physical Comfort (Com). Conversely, it is generally true that a high score on the remaining two scales, Work Pressure (WP) and Control (CtT) is indicative of a problem. However, in referring to the latter, this may not necessarily be the case if the other scores are high as well. For example, a tightly-knit group that produces a great deal, but is constantly under pressure, may still reflect.an overall positive work environment.

Descriptions of the ten W.E.S. subscales are found in Table I (see page 30$)$.

\section{HOSPITAL A}

The W.E.S. profile for the director shows a strong emphasis on the Relationship dimensions (i.e., Involvement, Peer Cohesion, and Staff Support). In the Personal Growth dimensions, there is also a strong

*Rudolf Moos, Combined Preliminary Manual: Family, Work, and Group Environment Scales (Palo Alto, California 94366: Consulting Psychologists Press, Inc., 577 College Avenue, n.d.), pp. 16-25. 
emphasis on Autonomy, with a moderate emphasis on Task Orientation. Work Pressure is seen as being fairly high; Innovation is seen as about Average; Physical Comfort is regarded as below average; and finally, there is little emphasis on Clarity and Control.

The workers' profile shows a moderate to strong emphasis on the Relationship dimensions of Peer Cohesion, Staff Support, and Involvement. Autonomy and Task Orientation (i.e., Personal Growth dimensions) are also strongly emphasized; Work Pressure and Clarity as to daily routines are seen as being fairly high; Control from the "top" is moderately below average; Innovation and Physical Comfort are seen as about average.

\section{Summary. (Hospital A)}

The workers from thịs milieu are highly committed to their jobs, have fairly close interpersonal/supportive relations with fellowemployees, and also feel reasonably supported by the director. Independent decision making is definitely encouraged and there is a very clear emphasis on good planning and efficiency. Workers, here, know what to expect from their daily routines, understand rules and policies, and are under pressure to keep up with their work loads. The director, however, does not control workers' activities. New approaches to tasks and pleasant physical surroundings are about average as compared to other work environments.

The supervisor agrees fairly closely with the workers' assessment of the milieu on five subscales: Involvement, Work Pressure, Control, Innovation, and Physical Comfort. Whereas there is agreement on the fact that Peer Cohesion, Staff Support, and Autonomy exist in the work 
milieu, the director sees these areas as being quite a bit more positive than do the workers. On the other hand, the workers see the milieu as encouraging Task Orientation and Clarity (i.e., over two standard deviations apart on the Clarity subscale) more than does the director.

In general, the impression is that this work environment is very positive (see Figure 1).

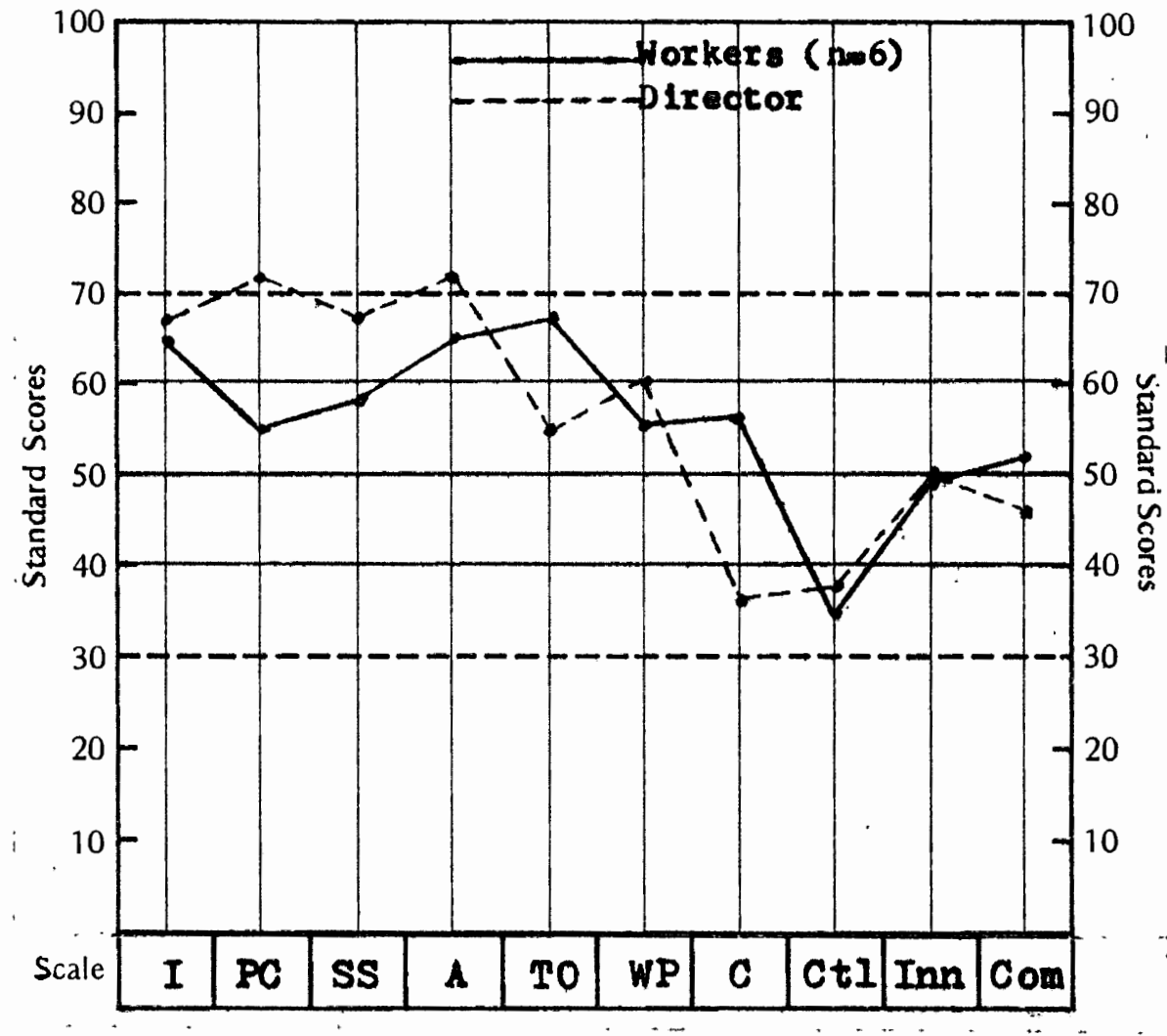

Figure 1. Hospital A

HOSPITAL B

The W.E.S. profile for the director shows an exceptionally strong emphasis on both the Relationship dimensions (i.e., Involvement, Peer Cohesion, and Staff Support) and the Personal Growth dimensions consisting of Autonomy and Task Orientation.' Work Pressure is seen as being 
only moderately high while there is little emphasis on Control from "the top." Clarity and Innovation are seen to be moderately to highly emphasized with Physical Comfort as being below average.

The workers' profile shows a work milieu that de-emphasizes the Relationship dimensions: Involvement is well. below average; Peer Cohesion is about average; and Staff Support is particularly de-emphasized (i.e., three standard deviations from the norm). In the Personal Growth dimensions, autonomy is moderately below average; while Task Orientation is seen as being moderately above average and therefore emphasized. Work Pressure is seen to have an exceptionally strong emphasis, and Control is also seen as being highly emphasized. There is little emphasis on Clarity, Innovation, and Physical Comfort.

\section{Summary (Hospital B)}

The workers at hospital $B$ show reservations as to the extent to which they are committed to and concerned about their jobs. Whereas there is an average amount of friendliness among employees, the supervisor is not seen as being supportive of workers. Independent decision making is not encouraged; the efficient performance of work tasks is moderately emphasized; and the press and urgency of work dominates this entire milieu. Rules and routines are relatively unclear to employees and the physical environment is extremely uncomfortable and unpleasant in appearance. Management maintains a high degree of control over employee activity and employees are not allowed to develop innovative approaches to their tasks.

There is virtually no agreement between the director's and the workers' assessment of the milieu on six of the subscales: Involvement, 
Staff Support, Autonomy, Clarity, Control, and Innovation. Where there is any semblance of agreement (i.e., the workers' and director's scores both fall at or on the same side of 50 ), the difference between the scores (i.e., on the average of one and one-half to two standard deviations away from each other) is also very important. For example, the director sees Work Pressure as being moderate and yet the workers feel the Work Pressure to be exceptionally high.

The biggest difference between the scores (i.e., approximately four and one-half standard deviations apart) is seen on the subscale of Staff Support. The director feels that he/she is highly supportive of the workers; however, the workers feel only limited support from the director.

Overal1, the impression is that this work environment is not very positive. In addition, there are large discrepancies between how the workers and how the director interpret this work milieu (see Figure 2). 


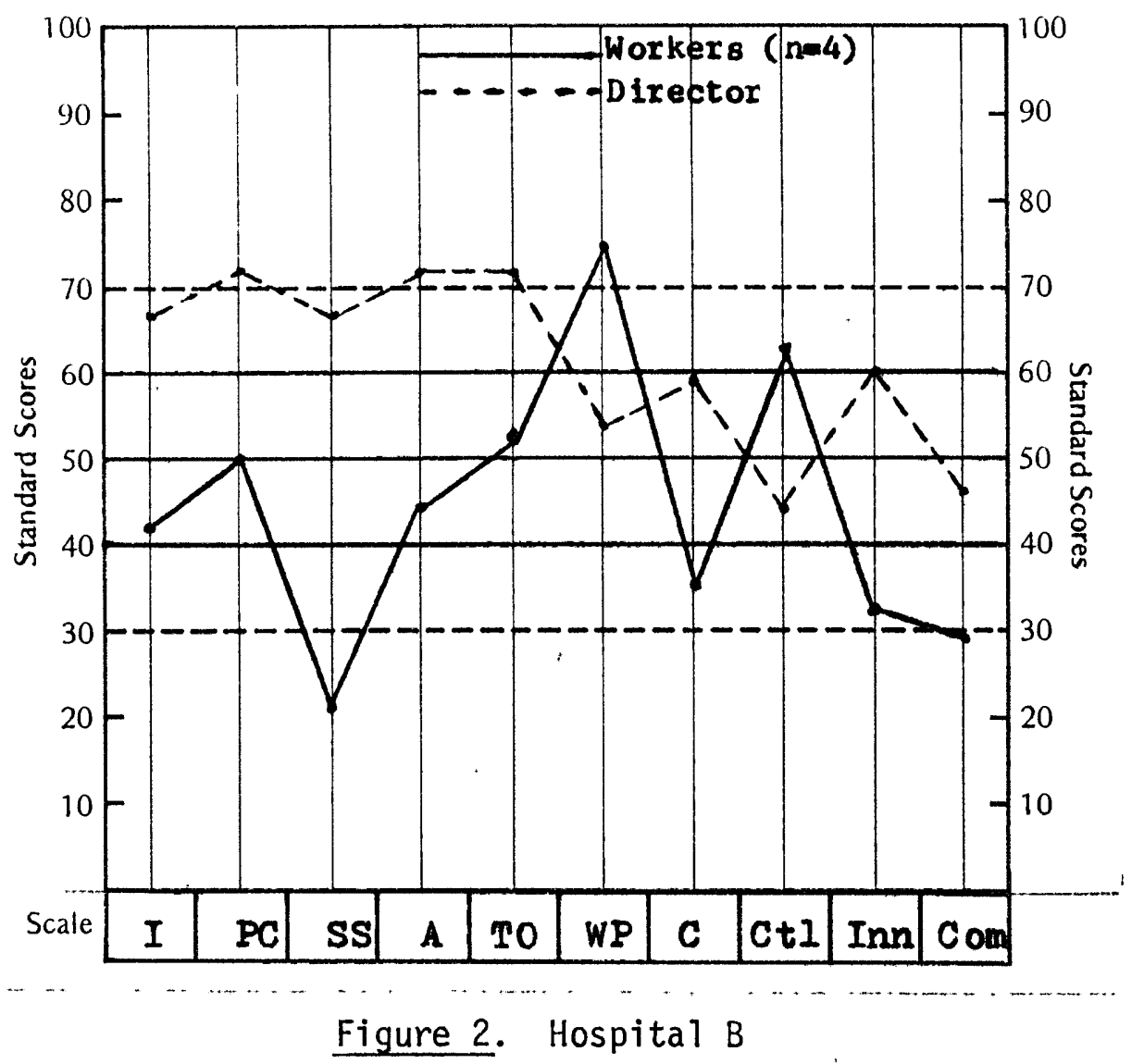

HOSPITAL C

The director's W.E.S. profile reflects a moderately high to strong emphasis on the Relationship dimensions of Staff Support, Peer Cohesion, and Involvement. Autonomy and Task Orientation are highly emphasized, with Task Orientation obtaining the highest score on this director's profile. Work pressure and Innovation are seen to be moderately emphasized; Control is rated as average; and Physical Comfort and Clarity are seen to be highly to strongly emphasized (respectively).

The profile of the workers shows, for the most part, an average emphasis in the Relationship dimensions, with Peer Cohesion being somewhat above average and Staff Support and Involvement being about 
average. This profile further displays a fairly high amount of autonomy, with a moderate emphasis on Task Orientation. Work Pressure is seen as being quite high with a moderate amount of Control coming from "the top." Clarity and Physical Comfort are rated as about average; and Innovation is felt, by the workers, to be moderately below average in comparison to other work environments.

\section{Summary. (Hospital C)}

The workers in this group are committed to their jobs; give to each other a moderate amount of encouragement; and receive support on an average basis, from their director. Workers are also encouraged to make independent decisions while feeling the press and urgency of work. There tends to be a moderate amount of control over workers' activities on behalf of the director. Workers here emphasize good planning and efficiency; however, they do not feel the environment to be particularly receptive to innovative approaches to their tasks. Emphas is on Clarity and Physical Comfort are seen as being average in comparison to other work milieus.

Fairly close agreement is seen between the director and the workers' assessment of the environment in the area of Peer Cohesion and Control. The profiles reflect moderate agreement around the issue of Autonomy. Whereas there is agreement (i.e., scores falling at or on the same side of 50) in Involvement, Task Orientation, Work Pressure, Clarity, and Physical Comfort, the director's scores are quite a bit higher than those of the workers'. The largest discrepancies are in the areas of Involvement, Task Orientation, and Clarity. The workers are seen as being about average in these areas, whereas the director sees the 
environment as having a much higher emphasis on these three areas than do the workers. On the other hand, the workers are under more stress (i.e., Work Pressure) than the director believes that they are; and feel the environment to be less innovative and less supportive than does the director.

Overall, however, the impression is that this environment is a fairly positive one in which to work (see Figure 3 ).

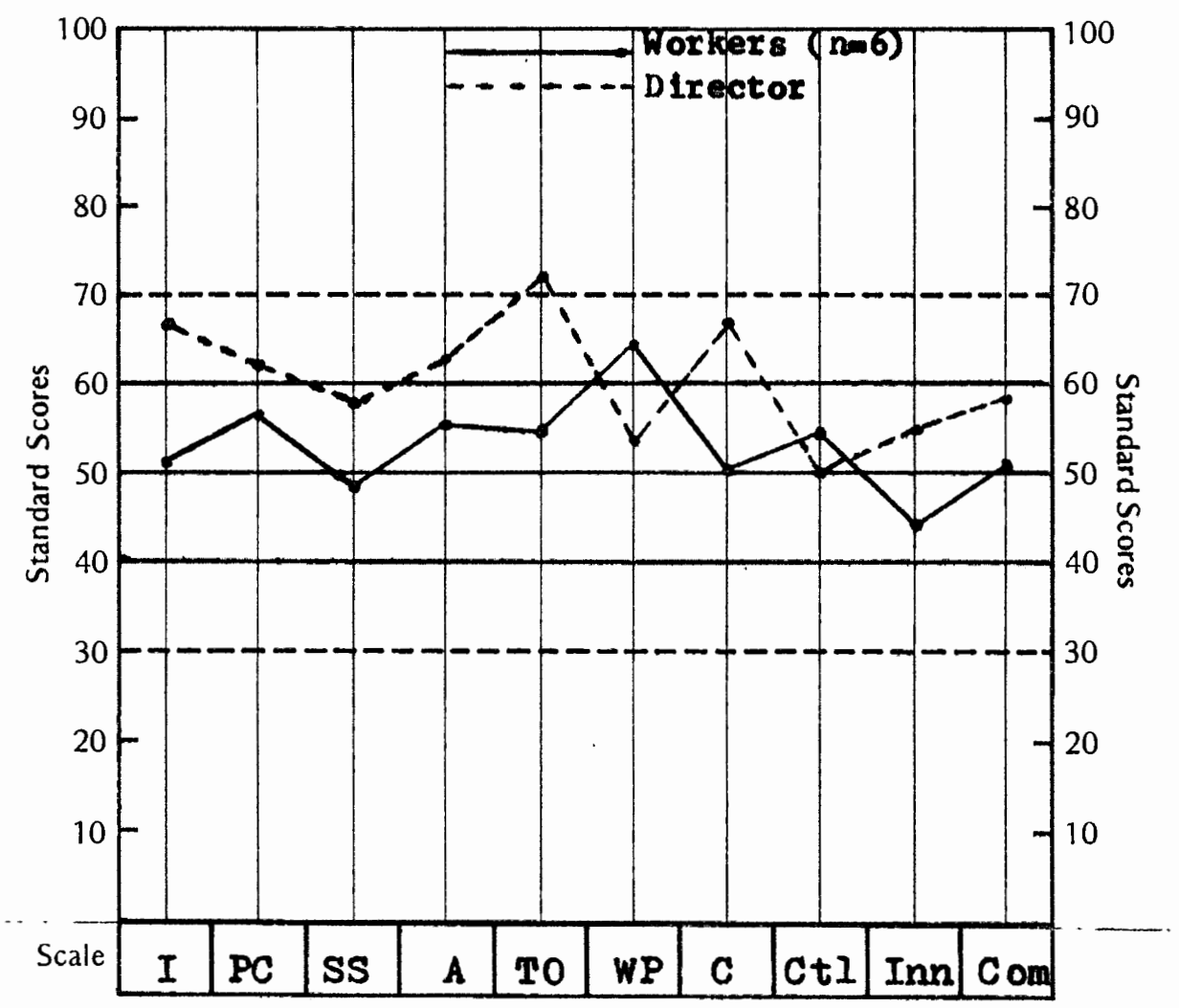

Figure 3. Hospital C

HOSPITAL D

The W.E.S. profile for the director shows a moderate to high emphasis in this work milieu on Staff Support and Involvement (respectively). The other subscale in the Relationship dimension, Peer Cohesion, 
is exceptionally high. In the Personal Growth dimensions, there is a strong emphasis on Autonomy, with a below average emphasis on Task Orientation. Two of the System Maintenance dimensions are de-emphasized: Clarity and Control. Work Pressure is seen as being very high. There is a moderate to moderately high emphasis on Innovation and Physical Comfort.

The W.E.S. profile for the workers of this hospital shows a lack of emphasis on the Relationship dimensions; Peer Cohesion is about average, but both Involvement and Staff Support are below average. On the Personal Development dimensions, Autonomy receives.a high emphasis, whereas Task Orientation is below average. There is very little emphasis in three of the System Maintenance dimensions: Clarity, Control, and Innovation. Work Pressure is seen as being moderately high, as is Physical Comfort.

\section{Summary (Hospita] D)}

The workers in this milieu reflect some hesitancy as to the degree to which they are involved in/committed to their jobs. Whereas employees are generally friendly to each other (i.e., average emphasis), this occurs in context of relatively little management and employee support of other employees. Independent decision making is encouraged, but efficiency and planning ahead are not emphasized. In this milieu, there is some sense of urgency about work output. Management does not maintain control over employee activity; rules and routines are relatively unclear to employees; workers are not encouraged to develop innovative approaches to their tasks; and the physical environment of the employees is felt to be comfortable and pleasant in appearance. 
The director does not agree, in this hospital, with the workers' assessment of the Relationship dimensions. Where there is a semblance of agreement (i.e., the scores of both the workers and director falling at or on the same side of 50), the difference between the Peer Cohesion scores (i.e., three standard deviations apart) becomes highly important. On the other hand, in the Personal Growth dimensions, there is agreement between the workers and director, although the director sees Autonomy existing to a greater extent than do the workers.. And finally, in the System Maintenance dimensions, there is agreement on the Physical Comfort subscale; disagreement (i.e.,, over two standard deviations apart) with regard to Innovation; and differences as to degree in the areas of Work Pressure, Clarity, and Control. It is interesting to note, however, that both the workers and director agree that very little Control is exhibited on behalf of management and secondly, that the director finds the milieu as being exceedingly unclear with respect to rules, routines, and procedures.

The impression is that this work environment, in general, is not a very positive one in which to work. However, unlike Hospital B, there are not nearly the discrepancies between how the workers and how the director interpret this work milieu (see Figure 4). 


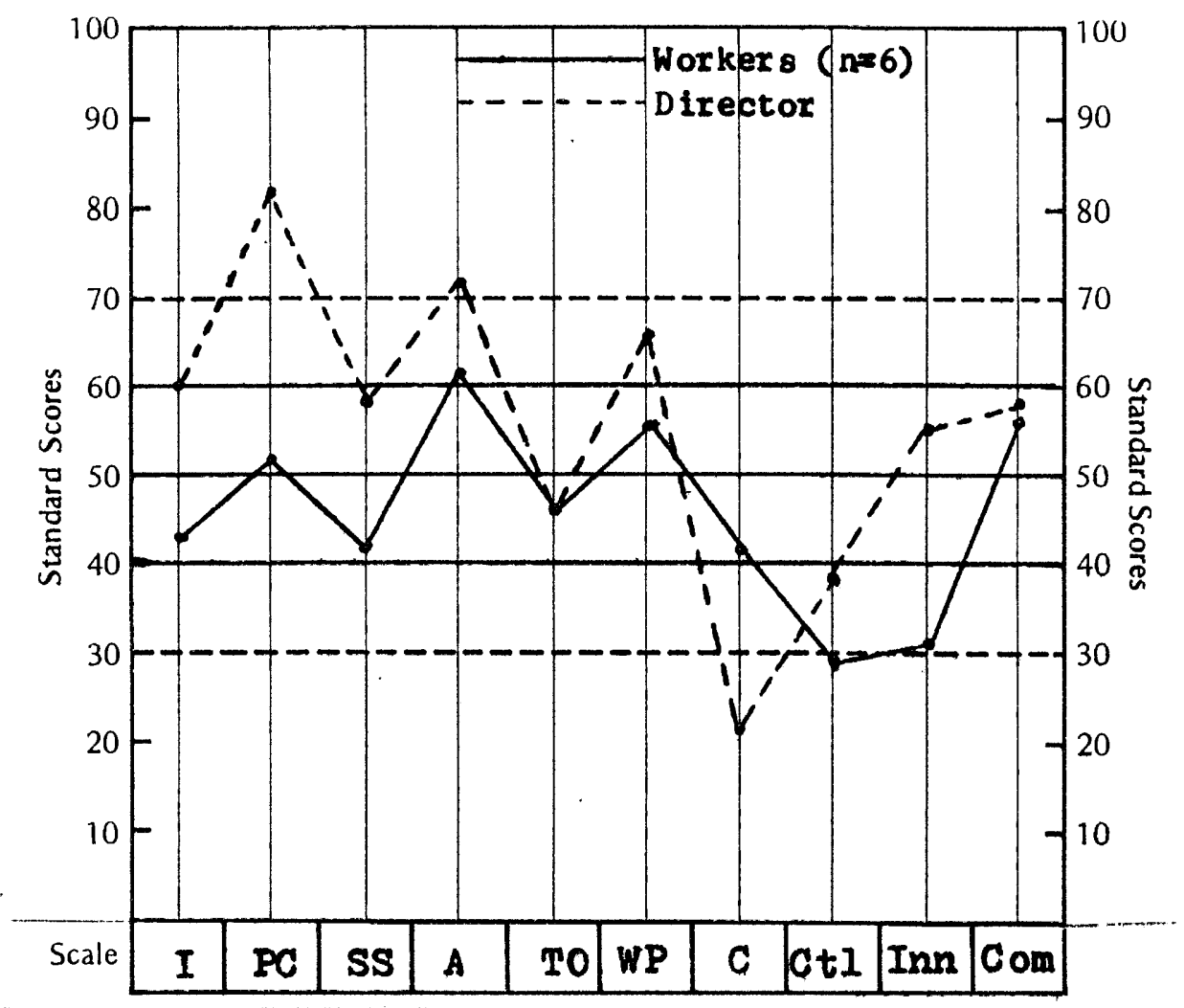

Figure 4. Hospital D

\section{HOSPITAL E}

This director's W.E.S. profile is distinguished by an exceptionally strong emphasis on the Relationship dimensions of Involvement, Peer Cohesion, and Staff Support. Autonomy is seen as being extremely high, while Task Orientation is rated below average. There is little emphas is on Work Pressure; Clarity and Innovation receive a strong emphasis; management Control is felt.to be about average; and. Physical Comfort is rated exceptionally high.

The workers' profile reflects a strong emphasis in the Relationship dimensions, although Staff Support shows about an average level of emphasis. Task Orientation and Autonomy (i.e.., Personal Growth/ 
Development dimensions) reveals a moderate to strong emphasis (respectively). The press of work is seen as being slightly below average, whereas Clarity and Control are seen as being emphasized. Innovation, in this environment, is not stressed; however, Physical Comfort receives a high emphasis.

\section{Summary. (Hospita1 E)}

From the viewpoint of the employees, this work milieu is characterized by a strong concern for and commitment to the job, close interpersonal relations with fellow-employees, and an average amount of support from the director. Workers are encouraged to make their own decisions and there is a very clear emphasis on "getting the job done." There are also very clear expectations regarding the daily routine, moderate management control of the warkers' activities, and very pleasant physical surroundings. New approaches to the tassk are not characteristic of this milieu and the press and urgency of work does not dominate the work environment.

Although there is basic agreement between the director and the workers in direction of the scores (i.e., scores falling at or on the same side of 50 ) on eight of the ten subscales, there are significant differences as to degree. For the most part, the director interprets this environment as being exceptionally positive, whereas the workers see the milieu as being only quite positive. The most important differences are in the areas of Staff Support and Innovation. The director believes that the milieu strongly emphasizes management and worker support of each other, whereas the workers' assessment reflects only average emphasis. Even more importantly, the director feels that variety, 
change, and new approaches are highly emphasized, whereas the workers do not believe that they are encouraged to be innovative.

Generally speaking, however, from the viewpoint of the workers, one has the impression that this work environment is very positive (see Figure 5).

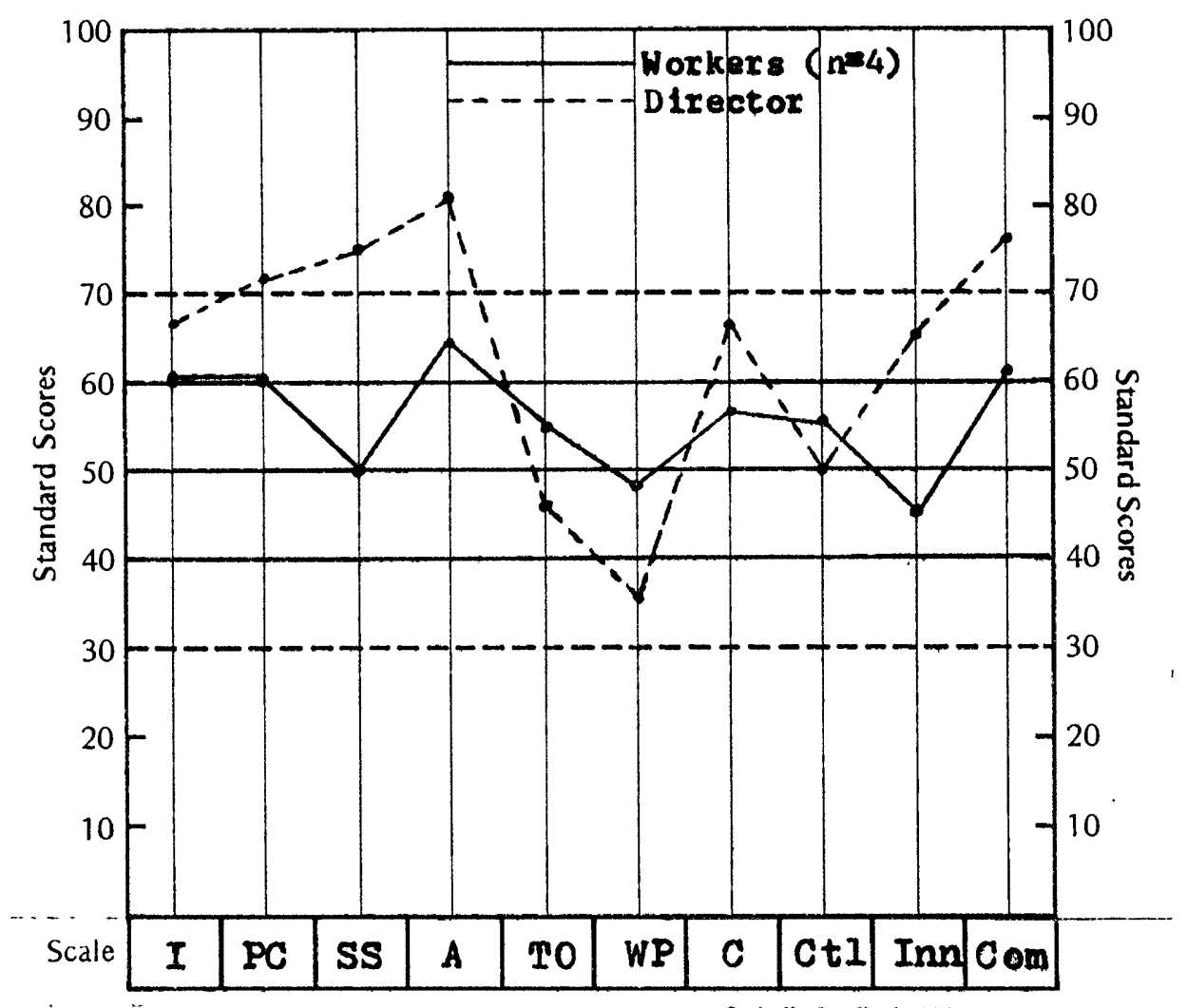

Figure 5. Hospital E

\section{HOSPITAL F}

The director's W.E.S. profile reflects an overall moderate emphasis on the Relationship dimensions, with Involvement being somewhat above average, Peer Cohesion being highly emphasized, and Staff Support being average. In the Personal Growth dimensions, there are opposite extremes; there is a strong emphasis on Autonomy, but Task Orientation 
is particularly de-emphasized. Two of the System Maintenance dimensions are seen to be moderately emphasized: Control and Innovation; and two of the System Maintenance dimensions are moderately de-emphasized: Clarity and Physical Comfort. Work Pressure is seen as being very high. On the workers' profile, there is a fairly strong emphasis on the subscales of Involvement, Peer Cohesion, and Autonomy. A moderate emphasis is seen with respect to Task Orientation, Work Pressure (moderately high), and Physical Comfort. (moderately low). Staff Support and Clarity are below average; Control is rated as being about average; and Innovation is seen as being de-emphasized.

\section{Summary (Hospital F)}

The work group is seen as having a relatively high commitment to/ concern for the job and strong, cohesive employee interactions. The director is seen as being supportive of workers on approximately an average basis as compared to supervisors in other work milieus. Workers at this hospital are strongly encouraged to be self-sufficient, make their own decisions, and to "get the job done." There is a definite sense of the press and urgency of work; however, employees are not encouraged, or are unable, to develop innovative approaches to their tasks. Management maintains average control over employee activity and there is a below average understanding as to what to expect regarding daily routines. Finally, work activity is carried on in reasonably pleasant physical surroundings .

The supervisor either agrees or fairly closely agrees with the workers' assessment of the milieu on five subscales: Involvement, Peer Cohesion, Staff Support, Clarity, and Control. Whereas there is 
agreement (i.e., the scores of both the director and the workers falling at or on the same side of 50) on two subscales, the director sees, and/ or experiences, Autonomy and Work Pressure more than do the workers. On the other hand, there is disagreement on three subscales: Innovation, Comfort, and Task Orientation. It is immediately apparent how far apart the scores are on Task Orientation (i.e., over four standard deviations), with the director interpreting the work milieu as totally de-emphasizing good planning, efficiency, and "getting the job done."

Overal1, the impression is that this environment is a positive one in which to work (see Figure 6).

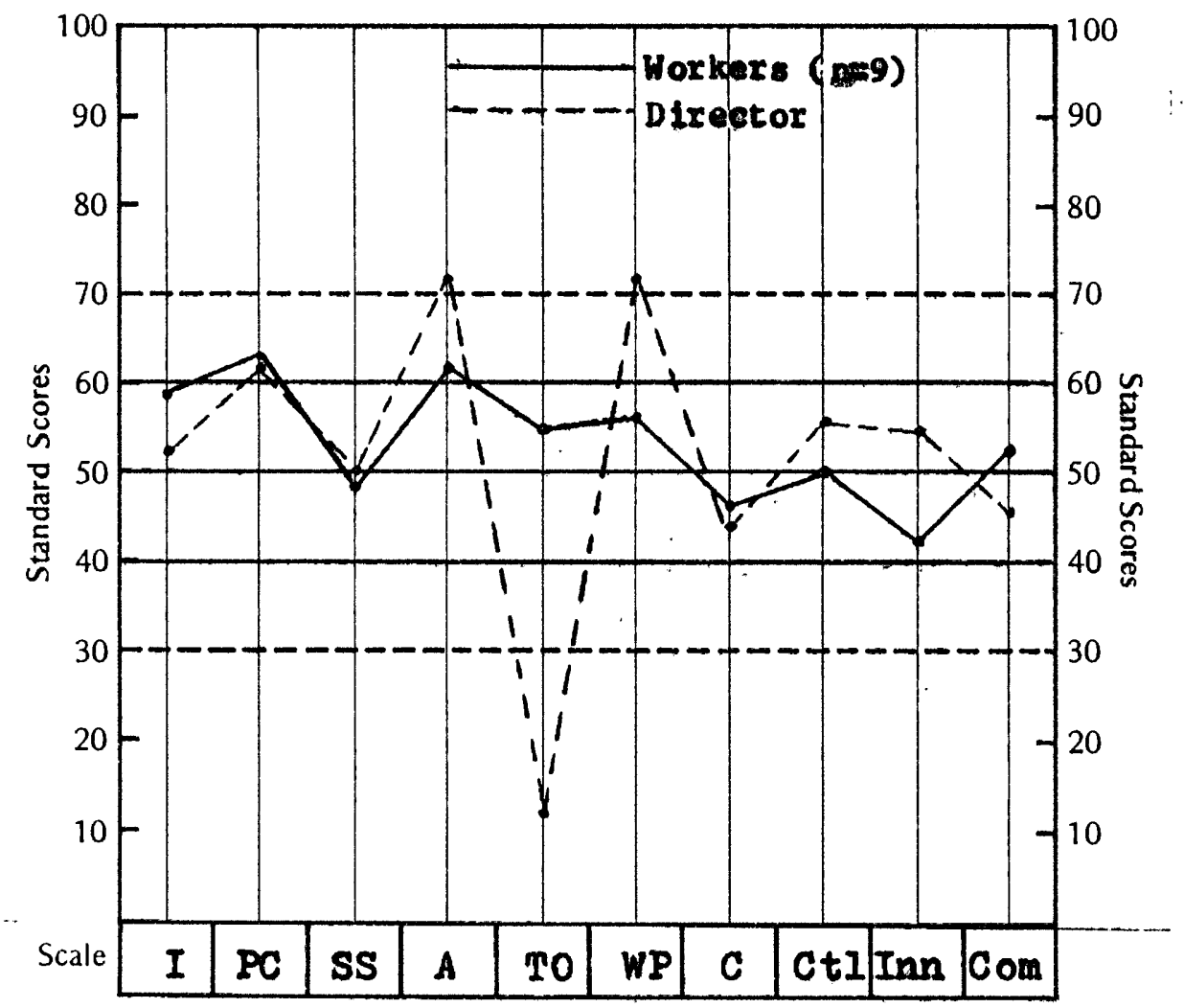

Figure 6. Hospital F 
HOSPITAL G

The profile for the director shows, in the Relationship dimensions, an average to strong emphasis on the subscales of Staff Support, Peer Cohesion, and Involvement (respectively). There is also a very strong emphasis in the Personal Growth dimensions, with Task Orientation being exceptionally high. Two of the five System Maintenance dimensions are highly emphasized: Work Pressure and Clarity; two are rated as being fairly high: Innovation and Confort; and one is well below average, or de-emphasized: Control.

The workers' profile reveals a milieu which de-emphasizes the Relationship dimensions of Involvement, Peer Cohesion, and Staff Support. Autonomy is seen as being moderately below average, with Task Orientation rated as being moderately above average. Work Pressure is felt to be, by the employees, very high. Aside from the press of work, the other System Maintenance dimensions (i.e., Clarity; Control, Innovation, and Comfort) are also de-emphasized.

\section{Summary (Hospital G)}

This work milieu is characterized by the workers as reflecting some hesitancy regarding concern for/commitment to the job. The press and urgency of work dominates the milieu and this occurs in a context of little cohesive, friendly employee interaction as well as management and employee support of other employees. Independent decision making is not encouraged, whereas there is a clear emphasis on good planning and efficiency (i.e., the Personal Growth dimensions). Rules and routines are relatively unclear to employees; there is little management control over 
employee activities; and the physical environment is somewhat uncomfortable and unpleasant in appearance. Finally, there is a slightly below average amount of variety, change, and new approaches to tasks.

There is close agreement between the director and workers on two of the subscales: Work Pressure and Control. On two other subscales, Staff Support and Task Orientation, there is agreement (i.e., scores falling at 50 or on the same side of 50); however, the director sees a much more positive orientation on both of the scales. There is basic disagreement as to the emphasis on the remaining subscales consisting of Involvement, Peer. Cohesion, Autonomy, Clarity, Innovation, and Physical Comfort. The director sees all six of these areas as being very positive and strongly emphasized, whereas the workers view them negatively and see the six areas as being de-emphasized. The largest discrepancy is on the subscale of Peer Cohesion, the scores being two and one-half standard deviations apart.

Generally speaking, the impression is that this environment is not a very positive milieu in which to work (see Figure 7). 


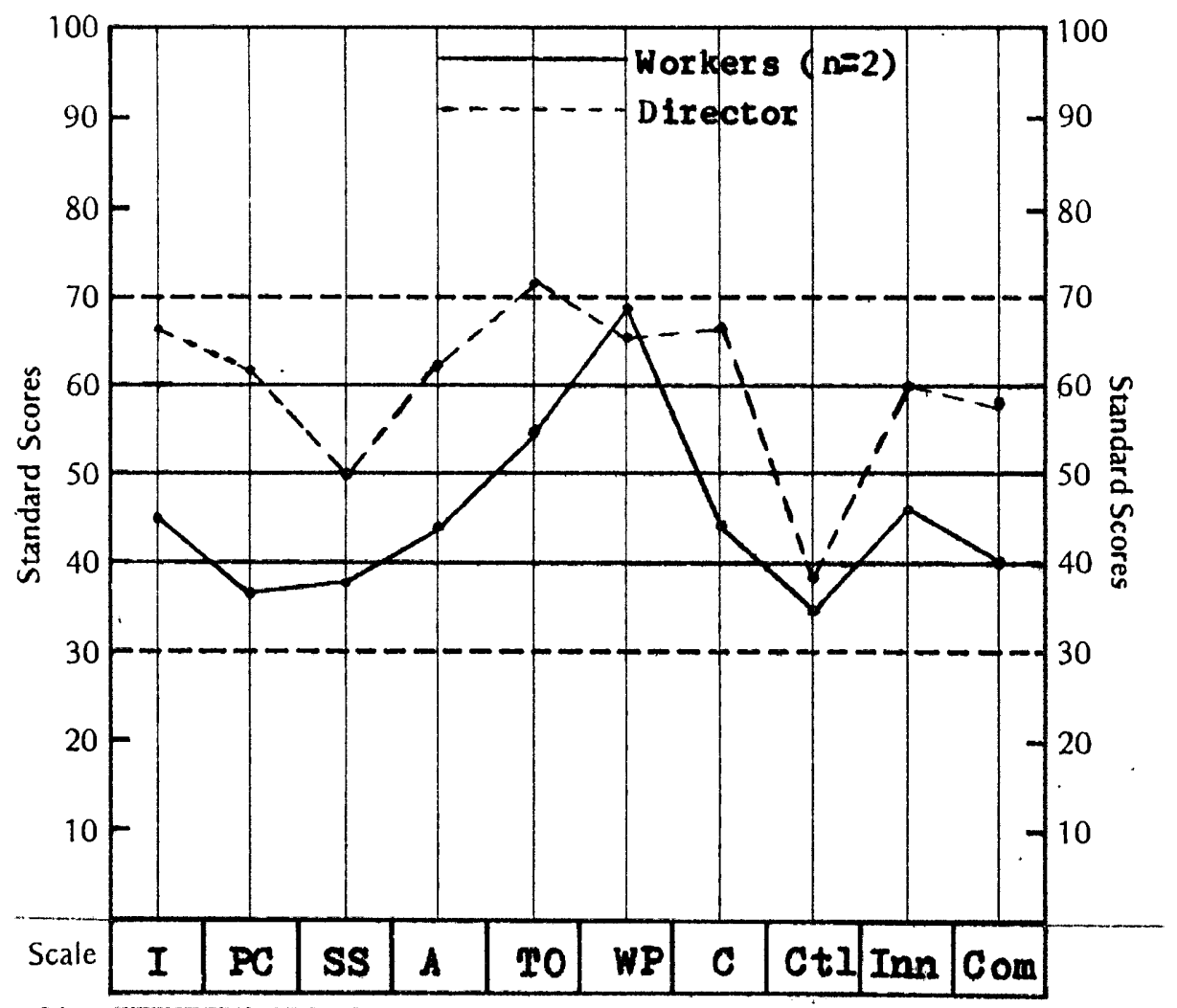

Figure 7. Hospital G

HOSPITAL H

In the Relationship dimensions, this director's W.E.S. profile shows a strong to very strong emphasis on the subscales of Involvement and Staff Support (respectively), whereas Peer Cohesion is deemphasized. Likewise, in the Personal Growth dimensions, Task Orientation is seen as being strongly emphasized, while Autonomy is deemphasized. Innovation is very highly emphasized on this profile; Clarity is rated as about average; and Work Pressure and Control are deemphasized. Physical Comfort is seen as being moderately high.

The workers' profile reveals an overall moderate emphasis on the Relationship dimensions of Involvement (moderate), Peer Cohesion 
(strong), and Staff Support (average). Autonomy is seen, by the workers, as being very high, and Task Orientation is felt to be about average (i.e., Personal Growth dimensions). Three of the System Maintenance dimensions are de-emphasized: Clarity, Control, and Innovation. Work Pressure is felt to be about average as. compared to other milieus, whereas Physical Comfort receives a strong. emphasis.

\section{Summary (Hospital H)}

The workers at Hospital $\mathrm{H}$ are committed to their jobs; have close personal relations among employees; are very. encouraged to be selfsufficient and make their own decisions; and work in very pleasant physical surroundings. However, these emphases occur in context of relatively unclear expectations regarding the daily routines and a lack of variety, change, and innovative approaches to their tasks. The director is seen as being somewhat supportive and the environment does not necessarily place an emphasis on good planning and efficiency: The press and urgency of work does not particularly characterize this environment, and management maintains relatively little control over employee activity.

The director agrees fairly closely with the workers' assessment of the work environment on three subscales: Involvement, Work Pressure, and Control. There is general agreement (i.e., scores falling at 50 or on the same side of 50) on three scales: Staff Support, Physical Comfort, and Task Orientation. However, the director believes that the milieu encourages, in particular, support and "getting the job done" quite a bit more than do the workers. There is disagreement on the remaining four subscales. It is interesting to note that the workers believe that the milieu encourages much more cohesiveness and independent 
decision making (i.e., two and two and one-half standard deviations apart, respectively) than does the director. On the other hand, the director feels that the environment reflects a great deal of innovation, which the workers do not feel. Nor do the workers agree with the director as to the extent of clear expectations regarding daily routines.

In general, however, the impression is that this overall work environment is positive (see Figure 8 ).

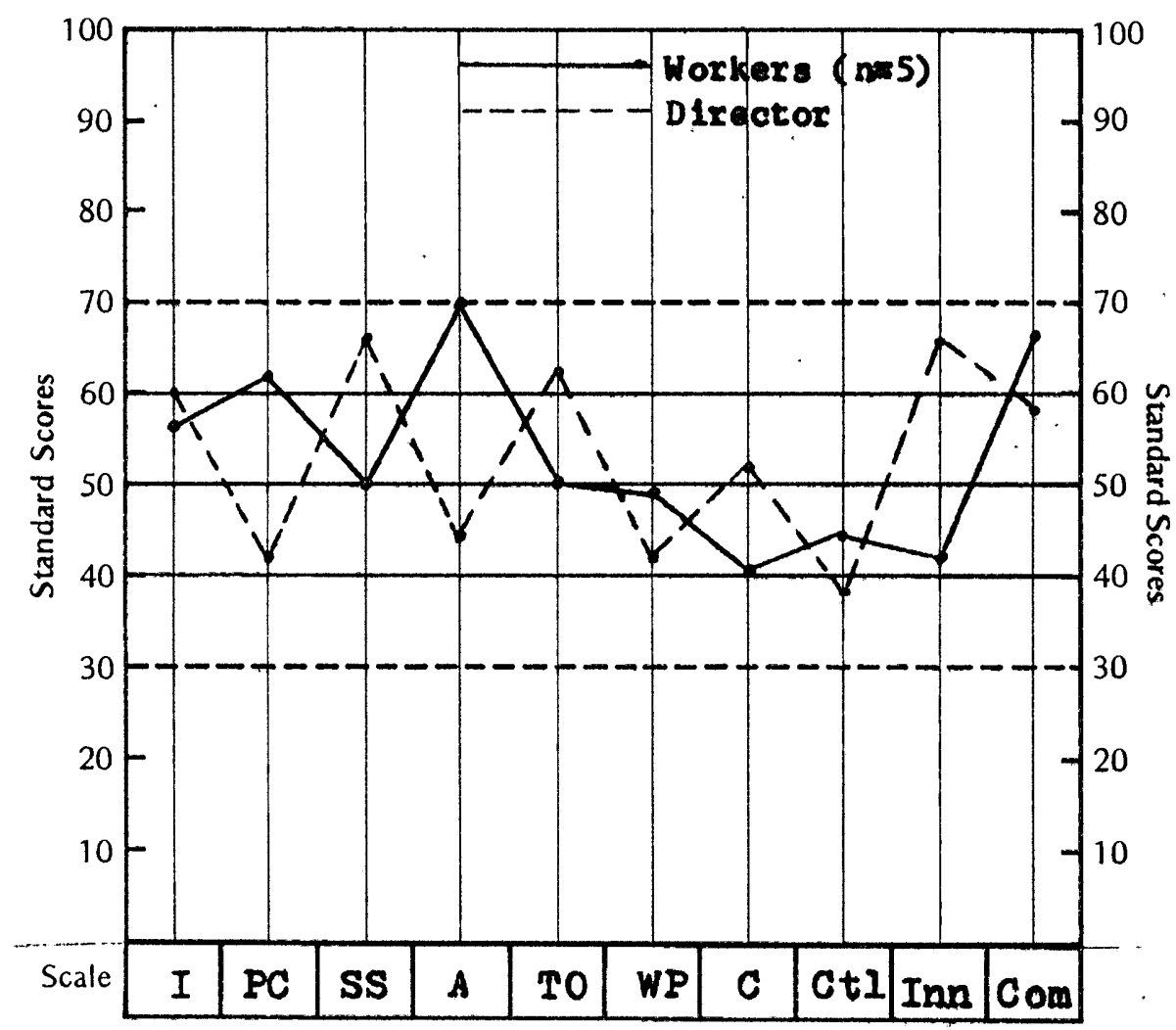

Figure 8. Hospital $\mathrm{H}$

\section{COMBINED PROFILES}

To develop the combined profiles, the mean standard score was taken in each of the ten subscales for directors, combined workers from each hospital, and students. 
Each of the three dimensions from the Moos Work Environment Scale (i.e., Relationships, Personal Growth, and System Maintenance and System Change) are presented separately. Within each of the dimensions, the scores are analyzed for the directors, workers, and students (see Figure 9).

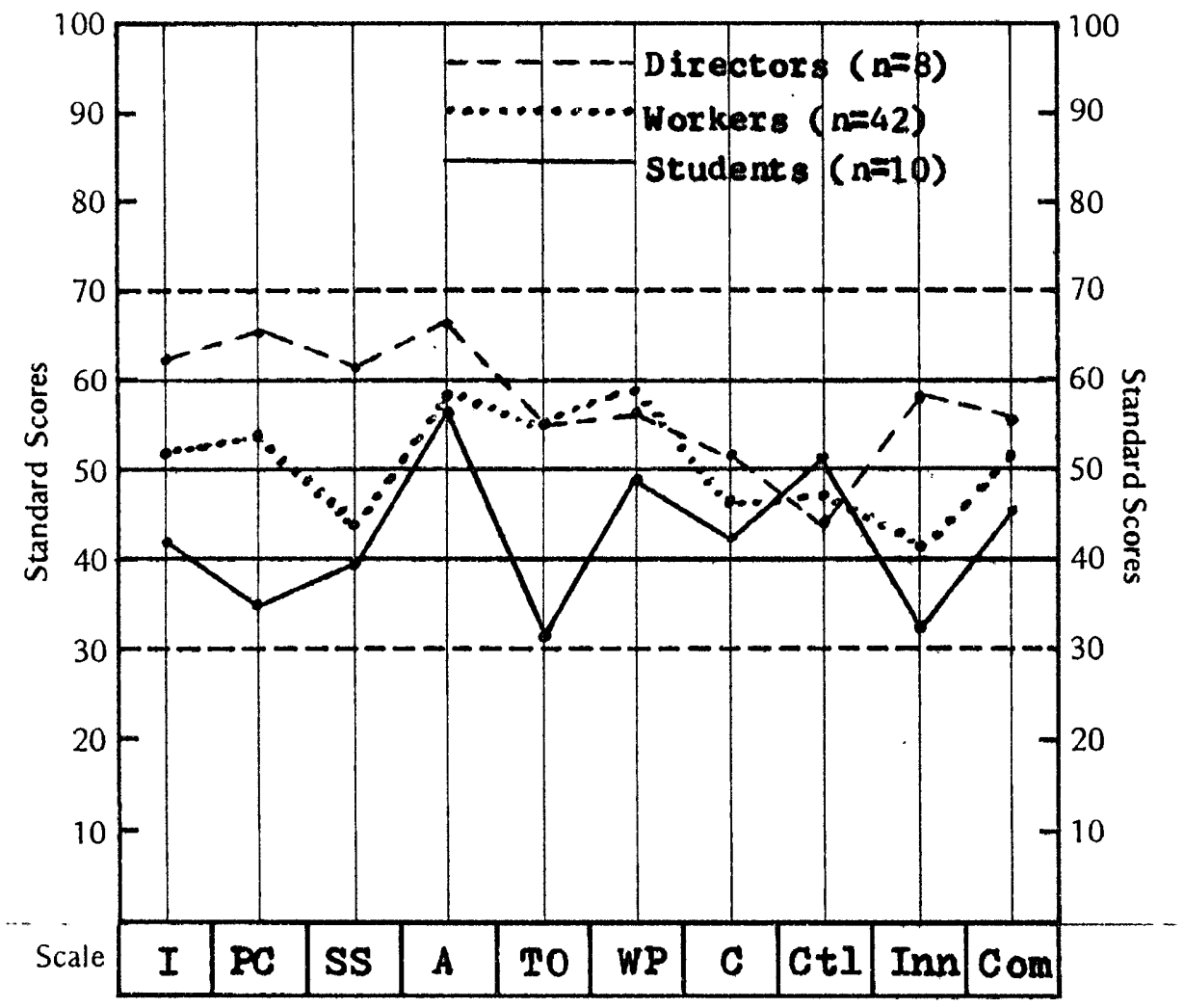

Figure 9. Combined Profiles

Relationship Dimensions

In the Relationship dimensions (i.e., Involvement, Peer Cohesion, and Staff Support), the directors, as a group, show a very strong emphasis on all the subscales.

The workers' W.E.S. profile shows a slightly above average emphasis, as compared to other work groups, on Involvement, a moderate 
emphasis on Peer Cohesion, and a moderately low emphasis on Staff Support.

The students, as a group, experienced all three dimensions as being de-emphasized; in particular, that of Peer Cohesion.

Summary (Relationship Dimension). The directors generally believe that the hospital social work milieu is characterized by an enthusiastic commitment to the job, very close interpersonal relations among employees, and strong management and staff support.

The workers, however, are not nearly as positive in the above areas. Whereas there is most definitely some concern for and commitment to the job, such commitment could not be labeled "enthusiastic.". Secondly, whereas there is a very clear emphasis on Peer Cohesion (i.e., meaning there are cohesive, friendly employee interactions), such cohesiveness is not nearly as positive as the directors think it to be. And finally, the workers, as a group, are in disagreement with the directors (i.e., over one and one-half standard deviations apart) in the area of Staff Support. Directors are not seen as being particularly supportive or encouraging, and yet directors feel as if they are.

The students, as a group, reflect some hesitancy as to the extent to which they are concerned for/committed to their field placements. This occurs in a context of little friendliness and/or close interpersonal relations with others as well as little in the way of director (i.e., Management) support and encouragement (i.e., the scores of both students and workers are fairly close together on the Staff Support subscale). 
Personal Growth/Development Dimensions

The combined W.E.S. profile for the directors shows, in the Personal Growth dimensions (i.e., Autonomy and Task Orientation), an extremely strong emphasis on Autonomy, with a moderate emphasis on Task Orientation.

The workers' profile reveals a moderately strong emphasis on Autonomy and also, like the directors, a moderate emphasis on Task Orientation.

Likewise, as compared with the workers, the students' profile shows a moderately strong emphasis on Autonomy, but Task Orientation is completely de-emphasized.

Summary (Persona1.Growth/Development Dimensions). As a group, the directors believe that.workers are highly encouraged to be independent and to make their own decisions. In addition, the efficient performance, amidst good planning, of work tasks is also emphasized, though not nearly as much as independence.

In these dimensions, the workers are in basic agreement with the directors. Independent decision making is most definitely stressed; however, not to the extent that the directors believe, and there is a very clear emphasis on "getting the job done" (i.e., Task Orientation). Whereas students, like with workers, experience self-sufficiency and making their own decisions, good planning and efficiency with respect to tasks is not seen as emphasized. 
System Maintenance and System

Change Dimensions

For the directors, as a group, the W.E.S. profile reveals a moderate (i.e., Work Pressure, Physical Comfort) to moderately high (i.e., Innovation) emphasis on three of the System Maintenance dimensions. Clarity is rated as about average, while Control is moderately below average.

The workers' profile, on the other hand, shows three dimensions (i.e., Clarity, Control, and Innovation) as being moderately deemphasized, with Innovation showing the lowest score; one dimension as being moderately.high (i.e., Work Pressure); and one dimension, Physical Comfort, being about average.

The students, as a group, show average emphasis in two dimensions (i.e., Work Pressure and Control) on the profile; two dimensions, Clarity and Comfort, being moderately below average; and one dimension, Innovation, being exceedingly low.

Summary (System Maintenance and System Change Dimensions): As a group, the directors believe that the hospital social work milieu definitely encourages change and new approaches to tasks, while employees are under the press and urgency of work in pleasant physical surroundings. They do not see themselves as maintaining control over employee activity, nor are there exceptionally clear expectations regarding the daily routines and rules of workers.

For the most part, the workers, as a group, agree fairly closely with the directors in all of these dimensions, with the exception of Innovation. They experience, in the milieu, a definite sense of the 
press and urgency of work, unclear expectations with respect to their routines, fairly limited management control over their activities, and adequate physical surroundings. On the other hand, unlike the directors, the workers do not feel that the hospital social work environment encourages variety, change, and innovative approaches to their tasks.

Finally, as a group, the students, when compared to the workers, feel quite a bit less work pressure, but experience more in the way of the environment's lack of encouragement in the area (i.e.,. Innovation) of change, variety, and new approaches to their tasks. Although there is somewhat less Clarity and Physical Comfort than workers as well as somewhat more in the area of management (i.e., the directors) control, the students agree fairly closely with the workers' assessment of the milieu in these areas.

\section{VARIANCE OF STANDARD SCORES}

\section{Discussion of Variance}

For the most part, the combined profile does reflect what directors, workers, and students feel about hospital social work. However, since the combined profile is based upon the standard score mean for each of the ten W.E.S. subscales for directors, workers, and students, a closer look at the variance of scores from the eight hospitals and ten students is in order (see Table II).

To begin, as the scores are averaged from each hospital, the variance between hospitals should decrease. This, in part, accounts for the fairly low variance of worker scores among hospitals as compared to the variance of student and director scores. However, one notices a 
TABLE II

MEAN AND VARIANCE OF STANDARD SCORES

\begin{tabular}{ccccccccc}
\hline \hline \multicolumn{3}{c}{ Directors } & \multicolumn{3}{c}{ Workers } & \multicolumn{3}{c}{ Students } \\
\hline $\begin{array}{c}\text { Sub- } \\
\text { Scale }\end{array}$ & Mean & Variance & Scale & Mean & Variance & Scale & Mean & Variance \\
\hline I & 63.5 & 4.94 & I & 52.8 & 7.89 & I & 42.7 & 17.65 \\
PC & 65.8 & 11.11 & PC & 54.5 & 7.88 & PC & 35.6 & 30.19 \\
SS & 61.5 & 8.38 & SS & 44.5 & 10.45 & SS & 39.9 & 24.50 \\
A & 67.4 & 10.34 & A & 58.3 & 9.02 & A & 57.0 & 15.01 \\
T0 & 54.9 & 18.89 & T0 & 54.6 & 5.60 & TO & 31.2 & 25.21 \\
WP & 56.2 & 11.59 & WP & 59.3 & 8.81 & WP & 49.8 & 15.88 \\
C & 51.8 & 15.70 & C & 46.7 & 7.40 & C & 43.4 & 12.90 \\
Ct1 & 44.0 & 6.70 & Ct1 & 47.2 & 10.43 & Ctl & 51.8 & 14.70 \\
Inn & 58.4 & 5.31 & Inn & 41.9 & 6.00 & Inn & 33.7 & 14.59 \\
Com & 55.8 & 9.45 & Com & 51.4 & 11.20 & Com & 46.6 & 10.20 \\
\hline
\end{tabular}

much smaller variance of scores among directors (i.e., $n=8$ ) than students. Consequently, it is safe to say that, as a group, the directors are much more cohesive in their opinions concerning the ten subscales than are the students. In fact, it is striking to note how small the variance scores of the directors are in the areas of Involvement and Innovation. In other words, the directors are very cohesive in their belief, in this case, that hospital social work reflects an enthusiastic commitment to the job amidst a moderately high emphasis on Innovation.

Aside from the subscales of Innovation and. Involvement, when one looks at the standard scores of each director, the variance for each of the subscales is more clearly understood. For example, Peer Cohesion had two extremes that accounted for the greater variance (i.e., 11.11): the director at hospital $\mathrm{H}$ saw Peer Cohesion well..below the mean (i.e., 42 vs. 65.8), while the director from hospital D saw Peer Cohesion as being well above the mean (i.e., 82 vs. 65.8). The other six directors 
saw this subscale as being strongly to very strongly emphasized, with three directors having scores of 62 and three directors having scores of 72. Thus, in all but one hospital, there is a high emphasis on Peer Cohesion, which is what the combined profile does, indeed, reflect.

Things are not quite as clear-cut, however, in the area of Task Orientation (i.e., "getting the job done"), which, for the directors, had the greatest variance (i.e., 15.70). On the combined profile, the score reflected a moderate overall emphasis in this area. The standard scores show, however, that only one hospital had a moderate emphas is (i.e., Hospital A). The others were quite diverse: a total of three directors (i.e., C, G, B) showed a very strong emphasis on Task Orientation; one (i.e., H) was strong; two (i.e., D, E) showed that it was moderately de-emphasized; and one (i.e., F) showed that it was totally de-emphasized. In fact, in comparison to the others, the director's score of 13 from Hospital F drastically lowered the mean for the Task Orientation category. Yet, in general, five of the eight directors did show a clear emphais on "getting the job done," which is what the overall profile reflects despite the difference regarding degree.

Workers

As previously mentioned, the variance of the scores on each of the ten subscales for the workers was obtained by using the average worker score from each hospital. Because of this averaging, the variance was generally smaller than the variance of scores for either the directors or students. It is interesting to note that for the workers, the variance was quite low (i.e., 5.97). in the area of Innovation. In other words, the workers generally agreed with the mean which, in this case, 
showed that the work environment does not emphasize/encourage the development of innovative approaches to their tasks. This is definitely reflected in the standard scores of all hospitals, with only two (i.e., hospitals $A$ and $G$ ) even approaching an average amount of Innovation, as compared to other work environments. And yet, the directors (i.e., note the low variance of scores for the directors on Innovation). appear convinced that the environment does encourage Innovation. This is an important discrepancy as the combined profiles of directors/workers, again, reveals.

According to the workers, two of the subscales that have the highest (i.e., only one other, Comfort, has greater variance) variance scores (i.e., Staff Support and Control), relate.: directly to the style of individual directors. For example, on the overall profile, Staff Support, with a mean score of 44.5 , is shown to be moderately deemphasized. If one looks at the standard scores for the eight hospitals under this subscale, only one hospital (i.e., A) is rated above average; two more hospitals (i.e., $E$ and $H$ ) are rated as being average; and finally, the remaining five hospitals are rated as being below average. The larger variance on the Staff Support subscale is accounted for by the degree to which the individual directors are seen as being nonsupportive. Again, the combined profile reflects at least the trend in this area of director support.

On the other scale, Control, the degree to which management (i.e., the directors) controls worker activity, the combined profile reflects a below to moderately below emphasis. In only one hospital (i.e., B) is there a strong emphasis on Control. However, two other hospitals (i.e., 
$E$ and $C$ ) have a moderate emphasis here; one (i.e., F) has an average emphasis; and four a very clear de-emphasis on this subscale. Therefore, four of the eight directors clearly de-emphasize Control, according to the workers.

For hospital social workers, the profiles show that the two highest mean scores are in the areas of Autonomy (i.e., 58.3) and Work Pressure (i.e., 59.3). Although their variances (i.e., 9.01 and 8.81, respectively) are not exactly low, independence and the press/urgency of work do seem to be characteristic of the hospital milieu. With resepct to Autonomy, five hospitals (i.e., A, D, E, F. H) showed a strong emphasis, one a moderately high emphasis (i.e., C), and only two a moderately low emphasis (i.e., B, G). Likewise, with Work Pressure, in three hospitals (i.e., B, C, G), the press/urgency of work dominated the milieu; in three more, it was moderately to highly felt; and only in two (i.e., E, H), was it felt to be slightly below average.

It is noteworthy that on the workers' Clarity subscale, the mean score, 46.7, was below to moderately below average, with a variance of 7.40. In only two hospitals (i.e., $A$ and $E$ ), did the workers experience clear expectations with respect to rules and daity. routines. In other hospitals, this area received an average emphasis in one (i.e., C) and was clearly de-emphasized in the remaining five (i.e., B, D, F, $G, H)$. The overall profile, therefore, once more reflects the trend among hospital social workers in the area of Clarity.

\section{Students}

The profile of the MSW students is particularly interesting, even though the variance, on all ten subscales, is fairly high. By looking 
at the standard scores along with the variance, it seems as if some clear trends emerge. For example, again, in the area of Innovation, six students, with standard scores of 23 , saw the work environment as completely de-emphasizing variety, change, and new approaches to tasks. Two other students, with scores of 44 and 39, saw Innovation as being clearly de-emphasized in the milieu, while only two of the ten students saw the environment as being average or above average in Innovation. The overall profile clearly reflects this trend that students, when considered as a group, did not feel that hospital social work for them encouraged innovative approaches to their tasks.

Secondly, in the area of Peer Cohesion (i.e., the extent to which workers are friendly and supportive of each other), five students felt that if it existed at all, that it did so on a minimal basis. The high variance (i.e., 30.19), however, reveals that one must take a closer look at the mean score of 36.6 . When this is done, not including the five previously mentioned students, one sees that three students felt a strong to exceedingly strong emphas is in this area, while two other students experienced Cohesion on a slightly above average basis. And yet, one-half of the students experienced an unfriendly/uncohesive environment, while four of these five students also felt that the hospital milieu had a minimal amount of Innovation. In short, whereas the variance seems to become important here, it also seems important that there is a trend toward a lack of cohesiveness for students.

Likewise, in the area of Task Orientation, the mean score is very low (i.e., 3l.2), while the variance is quite high (i.e., 25.21). The standard scores of the students reveal that for seven students, Task 
Orientation was clearly de-emphasized. On the other hand, three students experienced the hospital milieu as emphasizing this area. Therefore, again, the trend seems to be toward a clear de-emphasis of Task Orientation, which the overall profile illustrates.

Two other areas of special interest for hospital social work students would seem to be Staff Support and Clarity. The former would measure the extent to which the director/other workers are supportive of students; the latter would measure whether or not the students knew what to expect from their daily routines and how explicitly rules and policies were communicated to them. Both mean scores on these two subscales were fairly low (i.e., 39.9 and 43.4, respectively), while the variances were very different (i.e., 24.50 vs. 12.90). By looking at the standard scores, four students experienced minimal support from the director, one some support, one an average amount of support, and four with moderately strong to strong support. With respect to Clarity, there is a clearer trend: seven students saw this area as being clearly de-emphasized; two saw it as being strongly emphasized; and one student experienced an above average emphasis here. Especially in relation to the latter subscale, the overall profile does reveal the trend of both of these areas for students.

Finally, a note as to Autonomy. On the students' profile, this subscale received the highest score (i.e., 57.0). Eight students experienced an above average to exceedingly strong emphasis in this area, thus reflecting yet another trend toward high autonomy for this group of hospital social work students. 


\section{CONCLUSION}

This concludes the research portion of the project involving forty-two workers, eight directors, and ten students from Portland-area hospitals. Using the Moos Work Environment Scale, these sixty individuals were tested to assess what they thought/felt about their positions within a hospital setting. The overall results from the research as seen in relation to the "Literature Review" (i.e., Chapter II) are presented in the next chapter, "Conclusions and Recommendations." 


\section{CHAPTER V}

\section{CONCLUSIONS AND RECOMMENDATIONS}

The purpose of this project was to explore the field of hospital social work to see what, if any, frustrations, problem areas, and/or dissatisfactions existed among those who worked in this profession. The focus was on what hospital social workers thought and felt about their positions within a hospital setting. The overall project, therefore, consisted of a brief look at the history of hospital social work; a review of other studies done on hospital social workers; and a research study that assessed the attitudes, using the Moos Work Environment Scale, of forty-two hospital social workers, eight directors of hospital social service departments, and ten second year MSW students, toward the environment in which they worked.

\section{CONCLUSIONS}

The review of relevant 1 iterature (see Chapter II) seemed to uncover a struggling profession. Initially, workers belonged to both the hospital and the community. Consequently, they worked with patients while having a unique "social viewpoint." Such a perspective involved a great deal of work in the community, helping people to become socially rehabilitated. It, therefore, meant that workers had to be, by necessity, involved in social reform and community outreach. These rehabilitative efforts with patients occurred even though physicians and 
administrators of hospitals saw the primary function of the "social worker" as preventing the abuse of the public hospital from those who could afford care elsewhere. Physicians were especially resistant to social work endeavors.

Generally speaking, over the years, the more that social workers turned away from a unique "social viewpoint" by becoming more a part of only the hospital, the more clouded their role within the hospital became. As a profession, social work came to rely on the "psychological mode1" for casework and struggled to become a part of the "medical team" via the acceptance of the "medical model." In the process, social work was dominated by other professions. within the hospital setting; it had no power on the hospital organizational level and developed the stance of "being all things to all people" for the sake of "earning its keep."

A review of other studies on hospital social workers seemed to further emphasize some of their historical problem areas. One study (Heyman 1963), for example, showed the importance of social workers agreeing with physicians while working with patients; another (Gordon \& Rehr 1969) revealed the necessity of social workers developing a case-finding system if it was to set its own priorities within a hospital setting; and yet another study (01sen \& 01 sen 1968) showed the unwillingness of physicians to grant social workers more in the way of professional responsibilities.

The research portion of this project involving hospital social workers, directors, and students had varying results in relation to the history of the profession and other studies on workers. For example, in the study conducted here, directors were much more positive about 
social work within the hospital milieu than were workers. However, workers were, overall, generally more positive about their work environment than both the history and other studies would seem to indicate. According to workers, this author had the impression that five of the eight hospitals seemed to be relatively positive milieus in which to work. And likewise, although the students as a group experienced much in the way of dissatisfaction with hospital social work, a cluster of three to four of the ten students had consistently good experiences within the hospital setting.

Because the W.E.S. instrument measured ten different areas of the work environment, it was possible to identify areas of concern even if the worker(s) felt that, overall, the milieu was a positive one in which to work. One area of concern that this author immediately noticed was that of innovation. Due to the domination of social work by other professions within the hospital, the history and other studies would seem to indicate that hospital social work is not a very innovative field. The study conducted here would support this claim. "Most all of the students and the workers felt that innovation (i.e., change, variety, new approaches to tasks, etc.) was clearly de-emphasized in their jobs. And yet, without exception, the directors saw the hospital setting as definitely encouraging innovation. This seems to be an important discrepancy, for it would seem that in order to have the freedom to be innovative, the profession would have to have at least some power on the hospital organizational level to implement "change." The concept, therefore, of "earning our keep," "getting our foot in the door," etc. would further seem to discourage innovation, something that the history 
reflected. In fact, two studies reviewed here (U1 Iman et al. 1971; Pfouts \& McDaniel 1977) concluded that directors should concentrate on the organizational level for the sake of alleviating the "problems" in the field through developing "power" allowing for "change." One would have to wonder, therefore, how realistic the directors were in their assessment of the environment regarding innovation. For to see this area clearly, would require that the directors take an honest look at what they are doing to further the profession within the hospital organization.

Other areas of concern are not as clear-cut as the above area, Innovation. Clusters of workers, students, and directors interpreted their work environments similarly; however, there was never total agreement. As a result, . one is only able to say that generally speaking, this research study showed that workers were very independent; experienced the press and urgency of work; were not controlled nor particularIy supported by the directors; and did not have clear expectations with respect to rules and daily routines.

In view of the history and other studies on workers, some of the above areas are particularly interesting. For example, one would not expect workers to be so independent (i.e., six of the eight hospitals). One study (Pfouts \& McDaniel 1977), in fact, equated autonomy with being "Colleagues" rather than "Handmaidens." However, the autonomy occurs here amidst a lack of innovation (i.e.,. as shown by the workers from all eight of the hospitals), a definite sense of work pressure (i.e., as shown from six of the eight hospitals), a below average (i.e., as compared to other work groups) emphasis on control (i.e., as shown from 
four of the eight hospitals) and support (i.e., as shown from five of the eight hospitals) from the directors, as well as a lack of clarity (i.e., as seen at five of the eight hospitals) with respect to daily routines and rules.

The history of the profession would especially illuminate the last area mentioned above, clarity (i.e., increased ward work led to increased "cloudiness" with respect to "role"). Secondly, six of the eight directors actually do hospital social work themselves, which may account for a lack of control and support on behalf of directors. It may also be speculated that with directors directly involved in hospital social work, there would be little time for them to concentrate on the hospital organizational level.

The research portion of this project would further support the contention that the issue of hospital social work education must be more seriously addressed. Although three to four students had good experiences with the hospital setting, six to seven students had experiences that left much to be desired in various areas such as support and "warmth" from hospital social service staffs, innovation, and clarity as to what they were supposed to be doing as well as how to do it.

It is the author's belief that the purpose of this project, an exploration into the field of hospital social work, has been fulfilled. Based upon readings, research, and experience (the author was one of the ten hospital-based MSW students), recommendations for the field will now follow. 


\section{RECOMMENDATIONS}

Although recommendations for the future is a complex issue, there are some definite themes that can be briefiy stressed here. In addition, there are presently a few proven guideposts that may give some direction while progressing through the rugged terrain from now to the year 2000. For example, in 1972, the New York City Department of Public Health and twenty-three "public" hospitals designed the Ghetto Medicine Program (Schwartz \& Cohen 1973)... Since outpatients had been a long neglected group in America, the goal of the program was to "upgrade social services for patients using the outpatient.clinics and emergency rooms" (Ibid.,. p. 90). The Department had found that there were virtually no services being given to outpatients in these hospitals. These two areas of hospital care, clinics and emergency rooms, were therefore put under the authority of the Commissioner of Health. Services to outpatients were written into, the contracts with the hospitals. If hospitals failed to comply, they would lose money. Criteria that the evaluation teams would look for at the hospitals would be such things as: (1) social work staffing in outpatient clinics, (2) informational programs in the community on preventative health care, and (3) community organization programs geared toward the improvement of housing and mental health services. And since these areas would involve changes within the hospitals themselves, it was required that social services be included in the overall hospital decision- and policy-making process as well. Finally, each hospital would form Ambulatory Service Advisory Committees composed of community members. These committees were to be directly involved in the "planning, development, and evaluation of 
ambulatory care services" (Ibid., p. 91). This represented a reverse in the direction of medical care; for the first time, health needs were being defined by the community, not the health care field.

The Ghetto Medicine Program was an exciting return to hospital social work "roots" in a new and dynamic way. Some of its elements, the author believes, give the profession a starting point in formulating future trends. For one, hospital social workers should, broadly speaking, return to belonging to both the community and the hospital. This means an overall change in the current direction of the profession (i.e., specialization, ward work, etc.), for social work must begin rediscovering its unique social viewpoint. While working with outpatients, including discharged patients, workers must also return to being involved in social reform . . exploring community health needs and responding to them. In this way, they can begin the process of "throwing off" the medical "sickness" model and replacing it with a more preventative health outlook. By doing this, social workers will be in a better position to identify with, work, and adovcate for the consumers they are to serve, not the medical profession.

Hospital social. workers, therefore, need to, by necessity, get "their own house in order" . . clarifying what they can and cannot do. The directors of hospital social service departments must realize that social workers cannot be "all things to all people." In fact, to take this a step farther, the future of hospital social work may not even be on hospital.wards; work here seems to have resulted in identity diffusion, disorganization, and a lack of innovation and clarity, leaving workers, among other things, professionally voiceless: Furthermore, the 
author believes that workers will not be able to keep up with the exploding biomedical revolution that will occur in the next few decades. Should they attempt to do this, they will become so highly specialized on the individual wards that they will no longer even resemble their fellow workers in other branches of social work. In addition, as in the past, i.t will be impossible for social work education to provide the necessary specialized training to do this. While specialization is certainly the direction of medical education, social work education, along with being unequipped to handle it, does not have to be pulled along in the dark looking for traces of medical educational "footsteps." Rather, in the future, nurses, with continued better training, will perform many of the instrumental and affective tasks that social workers now (or would) perform on the wards. They will be in a much better position to participate in the medical revolution, not only react to it.

As hospital workers return to social rehabilitative efforts, they then will be in a better position to continue their quest for a professional identity. This will not be easy, but here is where, the author believes, their hope as well as their survival lies. Here is also where they will be able to quantify their value. For as this country moves into a national health insurance program, it will first be based on a limited medical "sickness-oriented" model. In time, with health as a human right, consumers will request more than this; social workers will serve as key advocates. As a result, the country will be obligated to adopt a much broader "social health system" model. Resources will then be needed in the areas of prevention, outreach, health maintenance, follow-up care, education, and social reform. "Social sources" of 
sickness (e.g., poverty, stress, etc.) will once again be emphasized, only this time the government as well as the medical profession will have to respond; they will not have the option to ignore any longer the realities of "whole community care." Alternative sources of health delivery will expand . . neighborhood health centers, home health care agencies, computerized self-diagnosis and care, etc. Social workers, in the midst of these changes and with a unique "social: viewpoint" identity of their own, will serve an important role in relation to the hospitals (and later, other health sources) and the community. This is the hope; to have vision, however, the profession must soon begin the struggle - . only then will it acquire wisdom: 
SELECTED BIBLIOGRAPHY 


\section{SELECTED BIBLIOGRAPHY}

Bartlett, Harriet M. "Ida M. Cannon: Pioneer in Medical Social Work." Social Service Review 49 (no. 2, 1975):208-229.

- Some Aspects of Social Casework in a Medical Setting. Chicago: American Association of Medical Social Workers, 1942.

Berkman, B. G., and Rehr, Helen. "Early Social Service Case Finding for Hospitalized Patients: An Experiment." Social Service Review 47 (no. 2, 1973):256-65.

Butrym, Zofia. Social Work in Medical Care. New York: Humanities Press, 1967.

Bracht, N. F. "Health Care: The Largest Human Service System." Social Work 19 (no. 5, 1975):532-42.

Cannon, Ida M. On the Social Frontier of Medicine. Cambridge: Harvard University Press, 1952.

Dana, Bess. "Social Work in the University Medical Center." Johns Hopkins Medical Journal 124 (no. 5, 1969):277:-82.

Field, Minna. "Family Sessions: A New Cooperative Step in a Medical Setting." Journal of Social Casework 30 (no. 10, 1949):417-20.

Goldstein, Dora. Expanding Horizons in Medical Social Work. Chicago: The University of Chicago Press, 1955.

Goldstein, Sidney E. "Hospital Social Service: Principles and Implications." In Proceedings: National Conference on Charities and Corrections, $p p .342-50$. Fort Wayne: The Archer Printing Co., 1910.

Gordon, Barbara, and Rehr, Helen. "Selectivity Biases in Delivery of Hospital Social Services." Social Service Review 43 (no. 1, 1969) :35-41.

Gordon, William E., ed. A Pilot Study of Medical Social Workers Interdiscipl inary Conferences. New York: NASW Press, 1956.

Hallowitz, Emmanual. "Innovations in Hospital Social Work." Social Work 17 (no. 4, 1972):89-98.

Harrington, Michael. The Other America. Baltimore: Penguin Books Inc., 1962. 
Heyman, Margaret M. "Collaboration between Doctor and Caseworker in a General Hospital." Journal of Social Casework 48 (no. 5, 1967): 286-92.

- Effective Utilization of Social Workers in a Hospital Setting. Chicago: American Hospital Association Press, 1962.

Lubove, Roy. The Professional Altruist. Cambridge: Harvard University Press, 1965.

Lurie, Abraham. "Social Work in Health Care in the Next Ten Years." Social Work in Health Care 2 (no. 4, 1977):419-28.

Lurie, Harry L., ed. Encyclopedia of Social Work. New York: NASW Press, 1965, pp. 127-29, 470-72.

McNamara, James. "Social Work Designs a Humanistic Program to Enhance Patient Care. Social. Work in Health Care 1 (no. 2, 1975-76): 145-53.

Meyer, Carol. Social Work Practice. New York: The Free Press, 1976.

Moos, Rudolf. Combined Preliminary Manual: Family, Work, and Group Environment Scales: Palo Alto, Calif, 94366: Consulting Psychologists Press, Inc., 577 College Avenue, pp. 16-25, n.d.

Morris, Robert, and Anderson, Delwin. "Personal Care'Services: An Identity for Social Work." Social Service Review 49 (no. 2. 1975) :157-74.

Moss, Celia R. Administering a Hospital Social Service Department. Washington, D.C.: American Association of Medical Social Workers, 1955.

Nacman, Martin. "A Systems Approach to the Provision of Social Work. Services in Health Settings: Part I." Social Work in Health Care 1 (no. 1,1975$): 47-53$.

"A Systems Approach to the Provisions of Social Work Services in Health Settings: Part II." Social Work in Health Care 1

(no. 2, 1975-76):133-43.

- "Social Work in Health Settings: A Historical Review." Social Work in Health Care 2 (no. 4, 1977):407-418.

01 sen, Katherine, and 01 sen, Marvin. "Role Expectations and Perceptions for Social Workers in Medical Settings." Social Work 12 (no. 3, 1968) : 70-78.

Pelton, Garnet. "The History and Status of Hospital Social Workers." In Proceedings: National Conference on Charities and Corrections, pp. 332-41. Fort Wayne: The Archer Printing Co., 1910. 
Pfouts, Jane H., and McDaniel, Brandon. "Medical Handmaidens or Professional Colleagues: A Survey of Social Work Practice in the Pediatrics Departments of 28 Teaching Hospitals." Social Work in Health Care 2 (no. 3, 1977):275-83.

Phillips, Beatrice; McCulloch, W. J.; Brown, M. J.; and Hambro, N. "Social Work and Medical Practice." Hospitals 45 (16 February 1971) : 76-79.

Phillips, Beatrice, and Solon, Jerry. "Social Services for Private Patients: A Case Study." Hospitals 34 (1 October 1960):34-39.

Rehr, Helen, ed. Medicine and Social Work: An Experiment in Interprofessional ism. New York: Prodist Press, 1974.

Richmond, Mary E. Social Diagnosis. New York: Russell Sage Foundation, 1917.

Schoenfield, Harvey. "Opportunities for Leadership for the Social Workers in Hospitals: An Administrator's Expectations." Social Work in Health Care 1 (no. 1, 1975):93-96.

Schwartz, A., and Cohen, A. "A Ghetto Medicine Program." Social Work 18 (no. 6, 1973):90-96.

Simmons, J. C.; Cooley, E. D.; and Hunt, R. S. "Social Work Program Meets Hospitals' Unique Needs." Hospitals 49 (no. 4, 1.975):64-66.

Stewart, J. C., and Lauderdale, M. "The Poor and the Motivation Fallacy." Social Work 17 (no. 6, 1972):34-37.

Ul lman, Alice; Goss, M.; Davis, M.; and Mushinski, M. "Activities, Satisfaction, and Problems of Social Workers in Hospital Settings." Social Service Review 45 (no. 1, 1971):17-29.

Volland, Patricia. "Social Work Information and Accountability Systems in a Hospital Setting." Social Work in Health Care 1 (no. 1, 1976) :277-85.

Wax, John. "Developing Social Work Power in a Medical Organization." Social Work 13 (no. 4, 1968):62-71.

Weinbach, R. W., and Dodge, D. D. "Educating for Discharge Planning." Hospitals 48 (no. 24, 1974):72-76. 
APPENDICES 


\title{
APPENDIX A
}

\author{
COVER LETTER
}

Dear

As a 2nd year MSW student at Portland State University, I want to study for my thesis/practicum, what hospital social workers feel about the environment in which they work. In order to do this, I'd like to administer to hospital social workers a short, true-false test (i.e., total time, 20 minutes), the Work Environment Scale (W.E.S.), written by Rudolf Moos.

This test is broken down into 10 subscales which, when combined, attempt to assess the over-all social climate of a given work unit. These subscales are: Involvement, Peer Cohesion, Staff Support, Autonomy, Task Orientation, Work Pressure, Clarity, Control, Innoyation, and Physical Comfort.

For the purposes of this study, I have defined "hospital social worker" as one who works on the nursing units of a given hospital, excluding mental health units. In other words, I am interested in those social workers who work on the hospital wards; not in the specialized clinics/programs affiliated with the hospital.

To those hospital social service departments that participate in the study, I will return to them: 1) A profile of their workers in the department (names will not be used), 2) Profiles of other hospitals involved in the study (the other hospitals, however, will not be identified by name, nor, otherwise, recognizable) \&, 3) An over-all profile of hospital social workers in Portland, broken down into the categories of directors, workers, and students. It is hoped that such data will help each department to assess their program by identifying strengths, areas of concern, etc.

In order to do this study, I will need permission to test both you and your workers. Once I have received your permission, I will call you to arrange a specific time for testing.

Enclosed you will find a permission slip. Please fill this out and return it as soon as possible. Your prompt reply will be greatly appreciated. 
If you have further questions, please call 229-7532 during the day (Tues.-Fri.) and leave a message if I am not available.

Sincerely,

Tim Haley

1609 SW 10th Ave. (\#309)

Portland, Oregon 97201 


\section{APPENDIX B}

\section{EXPLANATION OF PROJECT}

My name is Tim Haley and I'm a 2nd year graduate student in the MSW program at Portland State University. For my Master's thesis/ practicum, I am doing a research project on what hospital social workers think about the environment in which they work. In order to do this, I am administering the Moos Work Environment Scale to approximately 50 Portland hospital social workers from the 8 hospitals that have social service departments as we11 as 10 MSW students who are currently doing field placements in 5 of the hospitals. The test itself takes about 20 minutes and I assure confidentiality. I do not want any names on the answer sheets, however, I do ask that you record your degree (e.g., MSW, BSW, BA, etc.) on the back, of the answer sheet.

I've defined "hospital social worker" as one who works on the nursing units of a given hospital, excluding the psychiatric wards and the outpatient clinics. Are all of you here nursing unit workers? Are there any questions about this?

Once I analyze the data, I will return to each hospital: 1) A combined profile of their workers (i.e., with no names), 2) A profile of other hospitals (i.e., not recognizable by name or the number of workers) and, 3) A profile of all workers in Portland, broken down into the categories of directors, workers, and students. I ask that the director of the department recordhis/her title on the back of the answer sheet.

As you take the test. I ask that you answer the questions keeping in mind what environment and what people that you most closely identify with. In other words, some of you may be assigned to a particular floor and you know those people/that environment the best; others of you may identify more closely with your fellow-social workers and the actual social service department. So again, I ask that you answer the questions keeping in mind the environment that you most closely identify with. Any questions? 
APPENDIX C

STANDARD SCORES FOR DIRECTORS/WORKERS/STUDENTS

TABLE III

STANDARD SCORES (DIRECTORS); $n=8$

\begin{tabular}{|c|c|c|c|c|c|c|c|}
\hline A & B & C & $D$ & $E$ & $F$ & $G$ & $\mathrm{H}$ \\
\hline $\begin{array}{r}I-67 \\
P C-72 \\
S S-67 \\
A-72 \\
T 0-55 \\
W P-60 \\
C-37 \\
C t 1-38 \\
\text { Inn-50 } \\
\text { Com- } 46\end{array}$ & $\begin{array}{r}I-67 \\
P C-72 \\
S S-67 \\
A-72 \\
T 0-72 \\
\text { WP-54 } \\
C-59 \\
\text { CtI-44 } \\
\text { Inn-60 } \\
\text { Com-46 }\end{array}$ & $\begin{array}{r}I-67 \\
\text { PC-62 } \\
\text { SS-58 } \\
A-63 \\
\text { TO-72 } \\
\text { WP-54 } \\
C-67 \\
\text { Ct } 1-50 \\
\text { Inn-55 } \\
\text { Com-58 }\end{array}$ & $\begin{array}{r}I-60 \\
P C-82 \\
S S-58 \\
A-72 \\
T 0-46 \\
W P-66 \\
C-21 \\
\text { Ct } 1-38 \\
\text { Inn-55 } \\
\text { Com-58 }\end{array}$ & $\begin{array}{r}I-67 \\
P C-72 \\
S S-75 \\
A-81 \\
T 0-46 \\
W P-36 \\
C-67 \\
C t 1-50 \\
\text { Inn-66 } \\
\text { Com-76 }\end{array}$ & $\begin{array}{r}I-53 \\
P C-62 \\
S S-50 \\
A-72 \\
T 0-13 \\
W P-72 \\
C-44 \\
\text { Ct } 1-56 \\
\text { Inn-55 } \\
\text { Com-46 }\end{array}$ & $\begin{array}{r}I-67 \\
P C-62 \\
S S-50 \\
A-63 \\
T 0-72 \\
W P-66 \\
C-67 \\
\text { Ct1-38 } \\
\text { Inn-60 } \\
\text { Com-58 }\end{array}$ & $\begin{array}{r}I-60 \\
P C-42 \\
S S-67 \\
A-44 \\
T 0-63 \\
W P-42 \\
C-52 \\
\text { Ct } 1-38 \\
\text { Inn-66 } \\
\text { Com-58 }\end{array}$ \\
\hline
\end{tabular}

TABLE IV

STANDARD SCORES (WORKERS); HOSPITALS: $n=8$; WORKERS: $n=42$

\begin{tabular}{|c|c|c|c|c|c|c|c|}
\hline A & $B$ & C & $D$ & $E$ & $F$ & G & $\mathrm{H}$ \\
\hline $\begin{array}{c}I-64.6 \\
\text { PC-55 } \\
\text { SS-58 } \\
\text { A-64.6 } \\
\text { T0-67 } \\
\text { WP-55.8 } \\
\text { C-57.4 } \\
\text { Ct } 1-45.2 \\
\text { Inn-48.8 } \\
\text { Com-52 }\end{array}$ & $\begin{array}{c}I-42 \\
P C-50 \\
\text { SS-21 } \\
A-44 \\
\text { TO-53.4 } \\
\text { WP-75 } \\
\text { C- } 35.4 \\
\text { Ct }]-63.2 \\
\text { Inn-33 } \\
\text { Com-29.2 }\end{array}$ & $\begin{array}{c}I-51.4 \\
\text { PC-57 } \\
\text { SS-48.4 } \\
\text { A-56 } \\
\text { TO-55 } \\
\text { WP-64.2 } \\
C-50.4 \\
\text { Ct } 1-54.8 \\
\text { Inn-44 } \\
\text { Com-50.8 }\end{array}$ & $\begin{array}{c}I-43.8 \\
\text { PC-52 } \\
\text { SS-42 } \\
A-61 \\
\text { TO-46 } \\
\text { WP-55.8 } \\
C-41.6 \\
\text { Ct } 1-29.6 \\
\text { Inn-31.2 } \\
\text { Com-56.8 }\end{array}$ & $\begin{array}{c}I-60 \\
\text { PC-60 } \\
\text { SS-50 } \\
A-64.6 \\
\text { T0-55 } \\
\text { WP-48 } \\
\text { C-57.4 } \\
\text { Ct } 1-56 \\
\text { Inn-45.2 } \\
\text { Com-61 }\end{array}$ & $\begin{array}{c}I-58.4 \\
P C-63 \\
\text { SS-48.4 } \\
A-62 \\
\text { TO-55 } \\
\text { WP-57.6 } \\
C-46.4 \\
\text { Ctl-50 } \\
\text { Inn-43.4 } \\
\text { Com-53.8 }\end{array}$ & $\begin{array}{r}I-45 \\
P C-37 \\
S S-38 \\
A-44 \\
T 0-55 \\
W P-69 \\
C-44 \\
C t]-35 \\
\text { Inn-47 } \\
\text { Com-40 }\end{array}$ & $\begin{array}{l}\text { I- } \\
\text { PC- } \\
\text { SS- } \\
\text { A- } \\
\text { TO- } \\
\text { WP- } \\
\text { C- }\end{array}$ \\
\hline
\end{tabular}


TABLE V

STANDARD SCORES (STUDENTS); $n=10$

\begin{tabular}{rrrrrrrrrrr}
\hline \hline SSs & 1 & 2 & 3 & 4 & 5 & 6 & 7 & 8 & 9 & 10 \\
\hline I & 45 & 24 & 24 & 24 & 17 & 53 & 67 & 60 & 60 & 53 \\
PC & 52 & 2 & 12 & 0 & 0 & 72 & 82 & 52 & 62 & 22 \\
SS & 8 & 42 & 8 & 8 & 50 & 75 & 58 & 58 & 67 & 25 \\
A & 44 & 53 & 63 & 53 & 26 & 72 & 53 & 72 & 81 & 53 \\
T0 & 72 & 21 & 4 & 0 & 30 & 63 & 55 & 21 & 46 & 0 \\
WP & 78 & 54 & 36 & 30 & 72 & 60 & 42 & 42 & 54 & 30 \\
C & 52 & 44 & 67 & 29 & 44 & 59 & 44 & 37 & 37 & 21 \\
CtT & 68 & 74 & 56 & 32 & 62 & 56 & 62 & 32 & 38 & 38 \\
Inn & 23 & 23 & 23 & 23 & 23 & 66 & 50 & 44 & 39 & 23 \\
Com & 40 & 40 & 46 & 52 & 34 & 70 & 58 & 46 & 40 & 40 \\
\hline
\end{tabular}

